\title{
Integrated Analyses of Growth Differentiation Factor-15 Concentration and Cardiometabolic Diseases in Humans
}

Susanna Lemmelä ${ }^{1 *}$, Eleanor M. Wigmore ${ }^{2 *}$, Christian Benner ${ }^{1}$, Aki Havulinna ${ }^{1,3}$, Rachel M. Y. Ong $^{4}$, Tibor Kempf ${ }^{5}$, Kai C. Wollert ${ }^{5}$, Stefan Blankenberg ${ }^{6}$, Tanja Zeller ${ }^{6}$, James E. Peters ${ }^{7,8}$, Veikko Salomaa $^{3}$, Maria Fritsch ${ }^{9}$, Ruth March $^{10}$, Aarno Palotie ${ }^{1,11,12}$, Mark Daly ${ }^{1,11,12}$, Adam S. Butterworth $^{4,8,13,14}$, Mervi Kinnunen ${ }^{1}$, Dirk S. Paul ${ }^{2,4,13}$, Athena Matakidou ${ }^{2}$

\author{
Affiliations: \\ ${ }^{1}$ Institute for Molecular Medicine Finland (FIMM), University of Helsinki, Finland. \\ ${ }^{2}$ Centre for Genomics Research, Discovery Sciences, BioPharmaceuticals R\&D, AstraZeneca, \\ Cambridge, UK. \\ ${ }^{3}$ Finnish Institute for Health and Welfare, Helsinki, Finland. \\ ${ }^{4}$ British Heart Foundation Cardiovascular Epidemiology Unit, Department of Public Health and Primary \\ Care, University of Cambridge, Cambridge, UK \\ ${ }^{5}$ Department of Cardiology and Angiology, Hannover Medical School, Germany. \\ ${ }^{6}$ Clinic for General and Interventional Cardiology, University Heart Centre, Hamburg, Germany. \\ ${ }^{7}$ Department of Immunology and Inflammation, Faculty of Medicine, Imperial College London, London, \\ UK \\ ${ }^{8}$ Health Data Research UK Cambridge, Wellcome Genome Campus and University of Cambridge, \\ Cambridge, UK. \\ ${ }^{9}$ Bioscience Renal, Research and Early Development Cardiovascular, Renal and Metabolism (CVRM), \\ BioPharmaceuticals R\&D, AstraZeneca, Gothenburg, Sweden. \\ ${ }^{10}$ Precision Medicine, Oncology R\&D, AstraZeneca, Cambridge, UK. \\ ${ }^{11}$ Analytic and Translational Genetics Unit, Department of Medicine, Massachusetts General Hospital, \\ Boston, MA, USA. \\ ${ }^{12}$ Program in Medical and Population Genetics, Broad Institute of MIT and Harvard, Cambridge, MA, \\ USA. \\ ${ }^{13}$ British Heart Foundation Centre of Research Excellence, University of Cambridge, Cambridge, UK. \\ ${ }^{14}$ National Institute for Health Research Blood and Transplant Research Unit in Donor Health and \\ Genomics, University of Cambridge, Cambridge, UK.
}

\author{
*Susanna Lemmelä $\quad$ *Eleanor M. Wigmore \\ FIMM, \\ University of Helsinki AstraZeneca \\ Helsinki Cambridge \\ Finland UK \\ $\underline{\text { susanna.lemmela@helsinki.fi } \quad \text { eleanor.wigmore@astrazeneca.com }}$
}




\begin{abstract}
Growth differentiation factor 15 (GDF15) is a stress response cytokine that is elevated in several cardiometabolic diseases and has attracted interest as a potential therapeutic target. To further explore the association of GDF15 with human disease, we conducted a broad study into the phenotypic and genetic correlates of GDF15 concentration in up to 14,099 individuals. Assessment of 772 traits across 6,610 participants in FINRISK identified associations of GDF15 concentration with a range of phenotypes including all-cause mortality, cardiometabolic disease, respiratory diseases and psychiatric disorders as well as inflammatory markers. A meta-analysis of genomewide association studies (GWAS) of GDF15 concentration across 3 different assay platforms $(n=14,099)$ confirmed significant heterogeneity due to a common missense variant rs1058587 in $G D F 15$, potentially due to epitope-binding artefacts. After conditioning on rs1058587, statistical fine-mapping identified 4 independent putative causal signals at the locus. Mendelian randomisation (MR) analysis did not find evidence of a causal relationship between GDF15 concentration and cardiometabolic traits. Using reverse MR, we identified a potential causal association of body mass index on GDF15 (IVW $p_{\text {FDR }}=0.0072$ ). Taken together, our data do not support a role for elevated GDF15 concentrations as a causal factor in human cardiometabolic disease but support its role as a biomarker of metabolic stress.
\end{abstract}




\section{[Main Text:]}

\section{Introduction}

3 Obesity accounts for an estimated 2.8 million deaths worldwide and $2.3 \%$ of global disability-

4 adjusted life years (Organisaton.). Obesity has been causally linked to a variety of cardiometabolic

5 risk factors and diseases, including fasting insulin, systolic blood pressure and type 2 diabetes

6 (Holmes et al., 2014). Therefore, interventions to reduce obesity are recommended in the

7 management of these diseases (Yumuk et al., 2016). Currently, the most effective obesity

8 intervention is bariatric surgery (Jammah, 2015); however, its clinical utility is limited as it is

9 highly invasive and accompanied by a high risk of long-term complications such as

10 gastroesophageal reflux disease and nutritional deficiencies (Mesureur \& Arvanitakis, 2017). New

11 therapies such as GLP-1 receptor agonists aim to target obesity via appetite suppression but are

12 associated with common side effects including nausea and diarrhoea (Wilding et al., 2021). The

13 development of additional therapeutic strategies targeting obesity as an underlying cause and

14 pathology of cardiometabolic disease represents an area of unmet clinical need.

15 GDF15, a distant member of the transforming growth factor- $\beta$ family (Bootcov et al., 1997;

16 Emmerson, Duffin, Chintharlapalli, \& Wu, 2018), is upregulated in response to cellular stress and

17 several diseases, including cancer. It has been suggested that GDF15 functions as a stress response

18 agent implicated in organ injury (Kempf et al., 2006; V. W. W. Tsai, Husaini, Sainsbury, Brown,

19 \& Breit, 2018; Zimmers et al., 2005). GDF15 was originally identified to play a role in tumour-

20 induced anorexia/cachexia in mice through appetite regulation (Johnen et al., 2007). The body

21 weight reduction is considered to be mainly driven by food intake inhibition mediated by its

22 receptor GDNF-family receptor alpha like (GFRAL) in distinct areas of the brainstem (Emmerson

23 et al., 2017; Hsu et al., 2017; Mullican et al., 2017; Yang et al., 2017). GDF15 plasma levels are

24 elevated in animal models of obesity (Lockhart, Saudek, \& O'Rahilly, 2020; Xiong et al., 2017),

25 and administration of recombinant protein robustly lowers body weight in obese and diabetic

26 animals, including non-human primates (Mullican et al., 2017; Xiong et al., 2017). The beneficial

27 effects on glycemic control is considered to be mediated mainly by the body weight loss. Genetic

28 overexpression of Gdf15 results in decreased body weight and increased resistance to obesity 
medRxiv preprint doi: https://doi.org/10.1101/2021.12.15.21267719; this version posted December 16, 2021. The copyright holder for this preprint (which was not certified by peer review) is the author/funder, who has granted medRxiv a license to display the preprint in perpetuity.

It is made available under a CC-BY 4.0 International license .

associated with high-fat diets, whereas Gdf15 and Gfral deficient mice are more susceptible to diet-induced obesity (Mullican et al., 2017; O'Rahilly, 2017; Tran, Yang, Gardner, \& Xiong, 2018). Recent preclinical work has identified GDF15's role as a sentinel protein, upregulated in response to various ingested toxins triggering nausea-related behaviour in rodents assessed by pica and CTA (Conditioned Taste Aversion) (Borner, Wald, et al., 2020; Patel et al., 2019).

There is a lack of data supporting the treatment effect of GDF15 in humans. However, observational studies have revealed strong positive correlations of GDF15 plasma levels with body mass index (BMI), insulin resistance, age and mean arterial blood pressure (in obese individuals) (V. W. Tsai et al., 2015; Vila et al., 2011). Higher GDF15 levels have also been associated with all-cause mortality as well as mortality associated with heart failure and acute myocardial infarction, cancer, advanced heart failure and end-stage chronic kidney disease (Adela \& Banerjee, 2015; Khan et al., 2009; Nair et al., 2017; Wiklund et al., 2010). Metformin therapy, a type 2 diabetes treatment, has been shown to depend on GDF15 to lower body weight in mice and plasma GDF15 levels increased up to 40\% upon metformin therapy in humans (Coll et al., 2020; Day et al., 2019). Recent data suggest that GDF15 is involved in hyperemesis gravidarum (Fejzo, Arzy, Tian, MacGibbon, \& Mullin, 2018), supporting the hypothesis that GDF15 triggers anorexia and subsequent weight loss, at least partly, through the induction of malaise (Borner, Shaulson, et al., 2020). Mendelian randomisation (MR) has previously been applied to explore the causal relationship of GDF15 levels and cardiometabolic diseases, with causal associations reported for high-density lipoprotein (HDL) cholesterol and bone mineral density (BMD) (Cheung, Tan, Au, Li, \& Cheung, 2019; Folkersen et al., 2020). However, these analyses were based on small genetic studies for GDF15 and have not been replicated.

In this study, we used data from several large biobanks to conduct a systematic and extensive phenotypic and genotypic analysis of GDF15 with cardiometabolic traits and diseases, and to ascertain the causal relationship between GDF15 levels and cardiometabolic traits using MR and protein-truncating variant (PTV) analysis. 


\section{Results}

\section{$\underline{\text { Association of GDF15 plasma levels with } 676 \text { disease outcomes }}$}

To systematically assess the relationship between GDF15 plasma levels and clinical phenotypes, we utilised a large Finnish biobank, FINRISK. The FINRISK cohort comprises a cross-sectional population survey carried out over a 40-year period in Finland. GDF15 plasma levels were available for 6,610 participants from the 1997 recruitment cohort linked to 676 disease outcomes and were included in this analysis.

63 The median GDF15 concentration (measured using an immunoluminometric assay) was 796ng/L

64 (interquartile range, $\mathrm{IQR}=664-986$ ) (Supplementary Figure S1). First, we examined the 65 association of baseline characteristics with GDF15 plasma levels (Supplementary Table S1). Age 66 explained $28 \%$ of the observed GDF15 variance, with current smoking and BMI accounting for

$671.9 \%$ and $0.08 \%$ of the variance, respectively (Supplementary Table S2). Gender did not show a 68 significant association. All subsequent analyses have been corrected for these covariates (age, gender, smoking and BMI). Analyses corrected for age and gender alone are also presented for comparison (Supplementary Table S3 and S4), although results were similar.

71 We then investigated potential associations of GDF15 plasma levels with a range of disease 72 phenotypes (both prevalent and incident), focusing on the phenotypes defined by the FinnGen 73 consortium (T, Lahtela E, Havulinna AS, \& Consortium., 2020), as these endpoints have 74 undergone additional clinical validation (see Methods). A total of 676 disease endpoints were 75 examined as dependent variables in association analyses with GDF15 plasma levels (the 76 independent variable). After multiple-testing correction using false discovery rate (FDR, $\mathrm{P}_{\mathrm{FDR}}<$ 77 0.05), GDF15 was significantly associated with 80 disease endpoints (Table 1 and Supplementary 78 Table S5).

79 The most significant clinical associations observed were with all-cause mortality (logistic

80 regression odds ratio, $\mathrm{OR}=1.8, \mathrm{CI}=1.7-1.9, p$-value $=9.8 \times 10^{-27}$ ) and mortality due to cardiac 81 diseases $\left(\mathrm{OR}=1.8, \mathrm{CI}=1.6-1.9, p\right.$-value $\left.=7.7 \times 10^{-14}\right)$. We also observed significant associations 82 between GDF15 levels and type 2 diabetes $\left(\mathrm{OR}=1.5, \mathrm{CI}=1.3-1.6, p\right.$-value $\left.=2.2 \times 10^{-9}\right)$. Further, 
83 GDF15 plasma levels were significantly associated with cardiovascular diseases $(\mathrm{OR}=1.2$,

$84 \mathrm{CI}=1.1-1.2, p$-value $\left.=5.6 \times 10^{-6}\right)$, as well as subtype endpoints such as atherosclerosis, hypertension,

85 peripheral artery disease and stroke, and chronic kidney disease $(\mathrm{OR}=2.46, \mathrm{CI}=2.1-2.8, p$ -

86 value $\left.=4.4 \times 10^{-6}\right) \quad($ Table 1$)$. Additional positive associations were observed with respiratory

87 diseases, such as chronic obstructive pulmonary disease (COPD) and pneumonia, and psychiatric

88 disorders, including schizophrenia and mental and behavioural disorders due to psychoactive

89 substance use. Cancer phenotypes were also associated with GDF15 levels, including malignant

90 neoplasm of the respiratory system and intrathoracic organs $(\mathrm{OR}=1.6, \mathrm{CI}=1.3-1.8, p$-value $=0.0015)$

91 and malignant neoplasm of the bronchus and lung $(\mathrm{OR}=1.6, \mathrm{CI}=1.3-1.9, p$-value=0.0029).

92 GDF15 plasma concentration associates with prevalent and incident type 2 diabetes and

93 independently predicts all-cause mortality and cardiometabolic diseases

94 To determine the prognostic potential of GDF15 in predicting incident diabetes, we investigated

95 its plasma levels in relation to prevalent and incident type 2 diabetes in the FINRISK cohort. Type

962 diabetics (prevalent cases) had a 1.3-fold increase in median GDF15 levels compared to non-

97 diabetic controls (median difference=222ng/L). Furthermore, GDF15 levels were significantly

98 higher in prevalent diabetics (diagnosed at plasma sampling, $\mathrm{n}=37$; median=1,204ng/L) compared

99 to both incident cases (diagnosed after plasma sampling, $\mathrm{n}=500$; median= 992ng/L; Wilcoxon $p$ -

100 value $=0.008)$ and non-diabetic controls $\left(n=6003 ; 784 n g / L ;\right.$ Wilcoxon $p$-value $\left.=5.2 \times 10^{-11}\right)$

101 (Supplementary Figure S2). GDF15 plasma levels were also significantly higher in incident cases

102 than in non-diabetic controls (Wilcoxon $p$-value $=6.2 \times 10^{-51}$ ). Together, these data indicate that

103 increased GDF15 plasma levels could represent an early biomarker in pre-diabetic individuals.

104 Next, we carried out a Cox regression survival analysis on all-cause mortality, type 2 diabetes and 105 cardiovascular disease. During a 10-year follow-up period, 393 (6\%) study subjects had died, 97

106 (2\%) developed diabetes and 438 (7\%) developed cardiovascular disease. Models accounted for

107 blood pressure medication, smoking, total cholesterol, HDL cholesterol, BMI, prevalent

108 cardiovascular disease and mean systolic blood pressure. Our results revealed that GDF15 plasma

109 concentration is an independent predictor of all-cause mortality (hazard ratio, HR=1.7, $p$ -

110 value $\left.=9.2 \times 10^{-12}\right)$, type 2 diabetes $(\mathrm{HR}=1.40, p$-value $=0.02)$ and cardiovascular disease $(\mathrm{HR}=1.4$, 
medRxiv preprint doi: https://doi.org/10.1101/2021.12.15.21267719; this version posted December 16, 2021. The copyright holder for this preprint (which was not certified by peer review) is the author/funder, who has granted medRxiv a license to display the preprint in perpetuity.

It is made available under a CC-BY 4.0 International license .

$111 p$-value $=1.5 \times 10^{-6}$, Figure 1, Supplementary Table S6 and Figure S3). Individuals with GDF15

112 plasma levels above $967 \mathrm{ng} / \mathrm{L}$ (the upper quartile) were more than twice as likely to develop type

1132 diabetes compared to individuals with lower levels $\left(\mathrm{HR}=2.2, \mathrm{CI}=1.4-3.5, p\right.$-value $\left.=7.1 \times 10^{-4}\right)$.

114 Association of GDF15 plasma levels with 96 quantitative biomarkers

115 We then performed an association analysis of GDF15 plasma levels with 96 quantitative

116 biomarkers in FINRISK. After multiple-testing correction $\left(\mathrm{P}_{\mathrm{FDR}}<0.05\right)$, significant associations

117 were observed with 45 biomarkers, most notably, with blood markers known to be associated

118 with inflammation (Supplementary Table S7).

119 The most significantly associated biomarkers were mid-regional pro-adrenomedullin (MR-

120 proADM, beta $=0.24, p$-value $\left.=1.2 \times 10^{-91}\right), \mathrm{C}$-reactive protein $\left(\mathrm{CRP}\right.$, beta $=0.22, p-$ value $\left.=4.6 \times 10^{-64}\right)$

121 and hepatocyte growth factor $\left(\mathrm{HGF}\right.$, beta $=0.17, p$-value $\left.=4.2 \times 10^{-43}\right)$. All three markers have been

122 previously reported to be non-specifically elevated in a number of human diseases and have

123 known prognostic value (Jackson et al., 2016; Madonna, Cevik, Nasser, \& De Caterina, 2012;

124 Matsumoto, Umitsu, De Silva, Roy, \& Bottaro, 2017; Miller, Redfield, \& McConnell, 2007;

125 Peacock, 2014). Significant associations were also observed between GDF15 and components of

126 metabolic syndrome, specifically, levels of triglycerides (beta $=0.13, p$-value $=2.4 \times 10^{-22}$ ), fasting

127 insulin $\left(\right.$ beta $=0.10, p$-value $\left.=1.2 \times 10^{-13}\right)$ and waist-to-hip ratio $\left(\right.$ beta $=0.049, p$-value $\left.=7.0 \times 10^{-10}\right)$.

128 Genome-wide association studies of plasma levels of GDF15 quantified using 3 different

129 assays in 2 independent cohorts

130 We performed genome-wide association studies (GWAS) to identify the genetic determinants of

131 GDF15 plasma levels using two independent cohorts (FINRISK and INTERVAL) and three

132 GDF15 quantification methodologies (immunoluminometric assay in FINRISK and Olink and

133 SomaScan proteomic assays in INTERVAL; see Supplementary Materials). Results from

134 individual GWAS analyses are reported in Supplementary Tables S8-10. We then performed a

135 meta-analysis of the genome-wide significant variants identified in the GWAS performed in the

136 FINRISK, INTERVAL-SomaScan and INTERVAL-Olink cohorts to generate a combined statistic

137 and heterogeneity value. The analysis identified four genetic variants (rs1059369, rs1054221, 
medRxiv preprint doi: https://doi.org/10.1101/2021.12.15.21267719; this version posted December 16, 2021. The copyright holder for this preprint (which was not certified by peer review) is the author/funder, who has granted medRxiv a license to display the preprint in perpetuity.

It is made available under a CC-BY 4.0 International license .

138 rs1227734, rs189593084) at the GDF15 locus to be associated with GDF15 plasma levels ( $p$ 139 value $\left.<5 \times 10^{-8}\right)($ Supplementary Table S11).

140 Two variants had a strengthened signal in the combined meta-analysis, rs1054221 and rs1227734

141 (Supplementary Table S11), However, five genetic associations, which were genome-wide 142 significant for two of the three GWAS, displayed substantial heterogeneity, e.g. rs16982345 143 (heterogeneity $\mathrm{I}^{2}=99.8 \%$, heterogeneity $p$-value $=7.6 \times 10^{-180}$; Supplementary Table S11). By

144 exploring the LD structure between the heterogeneous variants (Supplementary Table S12), we 145 found that these variants were all located within the same LD block that included the missense 146 variant rs1058587 (p.H202D). Heterogeneity in GWAS results of GDF15 levels has been observed 147 in other studies (Jiang et al., 2018; Pietzner et al., 2020) and significant variations in GDF15 148 antibody binding affinity dependent on rs1058587 have been previously reported (Fairlie et al., 149 2001).

\section{Mitigation of epitope binding effects due to the rs1058587 missense variant}

151 To remove any potential epitope effects, we applied conditional analysis on rs1058587 when

152 linking plasma GDF15 concentrations with disease phenotypes and quantitative traits. A total of

15359 significant disease associations and 43 biomarker associations were identified. These 154 associations largely did not differ from the unconditioned results, although 21 fewer disease 155 associations reached significance (Supplementary Table S13-14).

156 To minimize confounding of the GWAS results from rs1058587 epitope effects, we conditioned 157 the association signal on chromosome 19 on rs1058587 in both FINRISK (Supplementary Table 158 S15) and INTERVAL-SomaScan (Supplementary Table S16). INTERVAL-Olink did not have a 159 significant association at this LD block. We then meta-analysed these conditioned GWAS. 160 Manhattan and Quantile-Quantile (QQ) plots of this GWAS meta-analysis are shown in Table 2, 161 Supplementary Figure S4 and Supplementary Table S15. We found 146 significant associations in 162 this region, with $r s 1227734$ identified as the strongest association (beta $=0.50, p$-value $=2.5 \times 10^{-187}$ ).

163 Fine-mapping this conditioned meta-analysis revealed four association signals with a causality 164 probability of 0.86 . The top configuration consisted of variants rs1054221 (beta=-0.50, $p$ - 
165

166

167

168

169

170

171

172

173

174

175

176

177

178

179

180

value $\left.=2.4 \times 10^{-184}\right), \quad$ rs3787023 $\quad($ beta $=0.04, \quad p$-value $=0.0017), \quad$ rs138515339 $\quad($ beta $=-0.27, \quad p$ value $\left.=3.2 \times 10^{-11}\right)$ and $\mathrm{rs} 141542836\left(\right.$ beta $=0.61, p$-value $\left.=1.9 \times 10^{-40}\right)$ and had a regional heritability of $7 \%$. Functional annotation and eQTL information can be found in Supplementary Table S18 and the Supplementary materials, respectively.

Mendelian randomisation analysis reveals no causal relationship between GDF15 plasma levels and cardiometabolic traits

Observed associations of GDF15 plasma levels with obesity-related diseases have been presented here and found in previous reports (V. W. Tsai et al., 2015; Vila et al., 2011) and variants in the GDF15 gene region have been associated with cardiovascular traits, cholesterol, waist-hip-ratio (WHR) and BMI (Wang et al., 2021). We therefore applied MR to assess the relationship between genetically-determined GDF15 plasma levels and BMI, WHR, glucose and type 2 diabetes. We also included HDL cholesterol and BMD as additional outcomes in our MR analysis due to the positive MR results in previous studies (Cheung et al., 2019; Folkersen et al., 2020).

We applied two-sample MR (Bowden, Davey Smith, \& Burgess, 2015) using LD clumping $\left(\mathrm{R}^{2}<\right.$ 0.1 , within $1.5 \mathrm{Mb}$ of either side of the lead $\mathrm{SNP}$ ) and identified eight independent genetic instruments from the conditioned meta-analysis on chromosome 19: rs1227734, rs62122429, rs1059022, rs181004295, rs75119307, rs11673678, rs138185133 and rs73923175 (regional heritability $=0.071$ ). Association statistics between the conditioned instrumental variables (IVs) and exposure (GDF15) were taken from the above meta-analysis, and the association statistics between the IVs and outcome were extracted from publicly available GWAS summary statistics (see Methods). These values were applied to a fixed effect inverse variance weighted (IVW) MR, as well as MR-Egger and MR-PRESSO methods (Verbanck, Chen, Neale, \& Do, 2018), in order to detect horizontal pleiotropy. MR using the conditioned variants did not find significant associations of genetically-determined GDF15 plasma levels with any of the examined traits. A nominal association was found with WHR but this did not pass multiple-testing correction (Table 3). Horizontal pleiotropy was detected in the association of genetically-determined GDF15 plasma levels with BMI (Global pleiotropy test $p$-value $=0.012$ ), HDL cholesterol (Global pleiotropy test $p$-value $=0.021$ ) and BMD (Global pleiotropy test $p$-value $=0.010$ ) using MR-PRESSO but not MR- 
medRxiv preprint doi: https://doi.org/10.1101/2021.12.15.21267719; this version posted December 16, 2021. The copyright holder for this preprint (which was not certified by peer review) is the author/funder, who has granted medRxiv a license to display the preprint in perpetuity.

It is made available under a CC-BY 4.0 International license .

193 Egger. We did not replicate findings of causality of genetically-determined GDF15 plasma levels

194 with BMD and HDL cholesterol, despite two independent studies suggesting otherwise (Cheung

195 et al., 2019; Folkersen et al., 2020).

196 Reverse Mendelian randomisation analysis identifies BMI as a causal factor for GDF15

197 plasma levels

198 We applied reverse two-sample MR (as described above) using GDF15 plasma levels as the

199 outcome variable to assess associations with BMI, WHR, glucose, diabetes, HDL cholesterol and

200 BMD. GDF15 GWAS summary statistics were taken from the conditioned meta-analysis of

201 GDF15 levels in FINRISK and INTERVAL. LD clumping was used to identify the genetic

202 instruments (see Methods). We found a significant association between higher genetically203 predicted BMI and higher GDF15 plasma levels (IVW estimate $=0.089, p_{\text {FDR }}=0.0072$ ) but not any

204 other tested trait (Table 4). Sensitivity analyses in MR-PRESSO but not MR-Egger analysis 205 confirmed the association with BMI ( $p$-value>0.05). MR-Egger identified horizontal pleiotropy 206 with WHR, however, MR-PRESSO identified horizontal pleiotropy with every trait other than 207 BMD. The finding of horizontal pleiotropy in MR-PRESSO but not MR-Egger suggests that the 208 causal of an apparent causal effect of BMI on GDF15 plasma levels warrants replication in larger 209 cohorts.

210 Effect of GDF15 protein-truncating variants on cardiometabolic traits in $\mathbf{3 0 2 , 3 8 8}$ 211 participants of UK Biobank

212 Carriers of GDF15 protein-truncating variants (PTVs) present an opportunity to explore the 213 phenotypic consequences of predicted loss-of-function (LOF) of GDF15 on human disease. We 214 analysed whole-exome sequencing data from 302,388 participants from the UK Biobank, of whom 215109 carried GDF15 PTVs in the heterozygous state (Supplementary Table S19). We assessed 216 differences in BMI, WHR, glucose, BMD, HDL cholesterol and type 2 diabetes between carriers 217 and non-carriers using the Mann-Whitney $U$ test. The analysis was restricted to unrelated 218 individuals of European ancestry, leaving 91 carriers of GDF 15 PTVs (male N=42, female N=49, 219 mean age=56.3) and 40,000 randomly selected European-ancestry non-carriers (male N=20,000, 
medRxiv preprint doi: https://doi.org/10.1101/2021.12.15.21267719; this version posted December 16, 2021. The copyright holder for this preprint (which was not certified by peer review) is the author/funder, who has granted medRxiv a license to display the preprint in perpetuity. It is made available under a CC-BY 4.0 International license .

220 female $\mathrm{N}=20,000$, mean age=56.9). In line with the $\mathrm{MR}$ analyses we observed no differences in 221 BMI (mean difference=0.1, $p$-value=0.90), WHR (male: mean difference $=0.01, p$-value $=0.64$, 222 female: mean difference $=0.01, p$-value $=0.55$ ), glucose (mean difference $=0.14, p$-value $=0.32$ ), 223 BMD (mean difference=0.02, $p$-value=0.82), HDL cholesterol (mean difference=0.08, $p$ 224 value $=0.08$ ) or self-reported diabetes ( $\mathrm{N}$ of diabetes in cases $=2, p$-value $=0.12$ ), suggesting that 225 mono-allelic GDF15 LOF does not have a strong effect on these traits. 


\section{Discussion}

228 In this study, we present a systematic phenotypic and genotypic analysis of GDF15 with a wide 229 range of health outcomes and biomarkers. In line with previous findings, our analysis confirmed 230 strong correlations of GDF15 plasma levels with a range of clinical parameters (e.g. age, smoking 231 and BMI) and human diseases (e.g. diabetes, cardiovascular and respiratory disease), as well as

232 several inflammatory biomarkers. As preclinical data in mice strongly implicated Gdf15 in the 233 aetiology of obesity and glucose tolerance, we specifically investigated whether human genetic 234 evidence supports these findings. Using data from large biobanks, we found that neither MR nor 235 GDF15 PTV analyses supported a causal role for GDF15 plasma levels within the normal range 236 in influencing BMI, WHR, glucose, diabetes, HDL cholesterol or BMD in humans. Instead, we 237 found that higher BMI may cause increases in GDF15 plasma levels highlighting the role of 238 GDF15 as a likely marker of metabolic stress in humans.

239 Access to the FINRISK cohort provided a valuable opportunity to explore GDF15 plasma level 240 associations with multiple phenotypes within a single large population. We found the strongest 241 associations with all-cause mortality and cardiometabolic diseases (cardiovascular disease and 242 diabetes), as well as cardiometabolic risk factors (e.g. hypertension, triglycerides, BMI), as 243 previously reported (Bonaca et al., 2011; Brown et al., 2002; Daniels, Clopton, Laughlin, Maisel, 244 \& Barrett-Connor, 2011; Ho et al., 2012; Kempf et al., 2007; Khan et al., 2009; Lind et al., 2009; 245 Rohatgi et al., 2012; Wiklund et al., 2010; Wollert et al., 2007). Our analyses also found that 246 GDF15 plasma levels are is a strong predictor of incident diabetes and an independent predictor 247 of all-cause mortality, cardiovascular disease and diabetes morbidity, suggesting its potential use 248 as a pre-diabetic prognostic biomarker. We found associations with neoplasms of the lung and 249 digestive system but not with other types of cancer. Our data further support the association of 250 GDF15 plasma levels with inflammatory phenotypes and biomarkers (CRP, mid-regional pro251 adrenomedullin) (Brown et al., 2007) and uncovered less well-described associations with 252 respiratory disease and psychiatric disorders. Despite previous observations suggesting a role for 253 GDF15 in anorexia (Borner, Shaulson, et al., 2020), we did not identify any association of GDF15 254 plasma levels with this trait. However, we note that statistical power may have been limited due 255 to the low number of cases (Supplementary Table S5). To identify phenotype associations in an 
unbiased way, we performed analyses encompassing all phenotypes available applying covariates

257 uniformly across all analyses. We note that covariates specific to a particular disease might have

258 been omitted introducing bias or leading to inflation or deflation of statistics. We detected a strong

259 association between GDF15 levels and smoking, which was recorded and adjusted in our analyses

260 as a binary phenotype. Smoking is an important contributing factor in multiple diseases and it is

261 therefore likely that adjustment as a continuous variable would have been able to better explain

262 the contribution of smoking to the phenotypic association signals, especially in respiratory disease,

263 lung cancer and some psychiatric disorders. These findings demonstrate that GDF15 plasma levels

264 are a general marker for risk in multiple diseases and are associated with non-specific biomarkers

265 such as CRP.

266 To define the genetic architecture of plasma GDF15 levels, we performed a GWAS meta-analysis

267 in two large cohorts, FINRISK and INTERVAL, across three different assay platforms. A striking

268 finding of this analysis was the substantial heterogeneity between variants across these studies,

269 consistent with previous reports (Jiang et al., 2018). Exploring the LD between the variants

270 displaying heterogeneity (Supplementary Figure S6) identified that a large proportion resided

271 within an LD block encompassing a common missense variant, rs1058587 (p.H202D). This variant

272 has been previously associated with hyperemesis gravidarum (Fejzo, Sazonova, et al., 2018) but

273 the presence of this missense variant within this locus raises the possibility of epitope artefacts,

274 indeed a previous study has identified epitope effects in this region (Fairlie et al., 2001). Therefore,

275 it is highly likely that the inconsistency in GWAS results across this locus is driven by differences

276 in the properties of the GDF15 assay used in each study (immunoluminometric assay in FINRISK,

277 SomaScan and Olink assays in INTERVAL). Therefore, it may be beneficial to adopt a more

278 consistent method for measuring GDF15 levels within the research environment. Approaches to

279 assay protein levels that don't involve binding to epitopes, such as mass spectrometry, will be

280 informative for avoiding potential artefacts due to protein-altering variants in the future.

281 Our analyses did not reveal a causal role for GDF15 plasma levels with any of these

282 cardiometabolic phenotypes. These results were further supported by the lack of association

283 between these phenotypes and GDF15 PTV carriers in the UK Biobank dataset. This is consistent

284 with a recent large-scale, pan-ancestry exome-sequencing study of over 640,000 individuals

285 exploring the associations of rare coding variants with BMI that did not report an association with 
GDF15 (Akbari et al., 2021). However, a meta-analysis completed by Cheung et al. (Ho et al., 2012) did identify significant associations of genetically-predicted GDF15 levels with HDL cholesterol (beta=-0.048, $p$-value=0.001) and estimated BMD (beta=0.026, $p$-value<0.001) which we did not replicate. The inclusion of differing covariates could have influenced the results of these analyses; our genetic analysis included only age, gender and principal components as covariates whereas the meta-analysis by Cheung et al. included age, gender, systolic blood pressure, antihypertensive medication use, diabetes mellitus and smoking status. Nevertheless, the larger sample size of the study presented here $(n=14,099)$ offered considerably improved statistical power over this previous study $(n=3,889)$.

This lack of causal association with GDF15 plasma levels suggests that GDF15 may behave differently in humans compared to rodents and non-human primates, where there are robust data demonstrating that GDF15 potently reduce body weight. GDF15 levels have also been demonstrated to provoke nausea-related pica and CTA responses in rat and mice, respectively (Borner, Shaulson, et al., 2020; Patel et al., 2019), as well as vomiting in shrews, suncus murinus, but studies in non-human primates report no signs of nausea (Xiong et al., 2017). Several clinical trials testing the safety and efficacy of GDF15 therapy have been planned or initiated but no data have yet been disclosed. Nevertheless, body weight loss in pregnant women suffering from hyperemesis gravidarium has been linked with higher plasma GDF15 levels (Fejzo, Arzy, et al., 2018). In FINRISK, information on nausea was not available but diseases with nausea as the main symptom were available (such as gastroesophageal reflux disease) and no significant association with GDF15 plasma levels was found $(\mathrm{OR}=1.1, \mathrm{p}=0.63)$. In pregnancy GDF15 levels are found at much higher serum levels than normal (A. G. Moore et al., 2000) and it is therefore possible that at higher levels GDF15 may induce nausea. Further studies into the effect of higher-concentration GDF15 in humans and the outcomes of clinical trials will elucidate its role further.

As our analyses did not support a causal role for GDF15 plasma levels in the phenotypes examined,

311 we sought to investigate if genetics supported the role for GDF15 as a consequence of these 312 conditions. We conducted reverse MR using GDF15 plasma levels as the outcome and the 313 previously assessed cardiometabolic traits and diseases as the exposures. We identified a 314 significant causal association of BMI on GDF15 plasma levels, suggesting that higher GDF15 
315 levels could be a consequence of higher BMI, supporting the recently reported role of GDF15 in 316 response to stress (Patel et al., 2019). However, the contradictory findings of horizontal pleiotropy 317 between MR-Egger and MR-PRESSO lead to residual uncertainty in the interpretation of the MR 318 analysis. It is possible that the heterogeneity found in our study caused by the use of different 319 assays is driving this pleiotropic finding. A recent report in a MR study of GDF15 levels performed 320 by the SCALLOP consortium also found a significant causal effect of BMI (IVW effect=0.20, $p$ 321 value $\left.=1 \times 10^{-7}\right)($ Folkersen et al., 2020). Our replication of this finding strengthens the evidence that 322 GDF15 levels are likely a consequence of differences in BMI rather than a cause. Further research 323 will be required to determine conclusively the role of horizontal pleiotropy in this relationship.

324 Using valid genetic instruments in MR is of key importance as an invalid instrument would violate 325 the assumptions of the model and lead to unreliable results. To minimise bias from differential assay binding, we conditioned on rs1058587 in our analyses, which could be overcautious. The association of rs1058587 with adiposity traits and hyperemesis gravidarum raises the possibility 328 that GDF15 exerts a causal effect that is not mediated by altered plasma levels, such as via altered proteoforms and/or altered GFRAL binding. With the use of a wide range of GDF15 assays and the possibility that this missense variant is impacting the assay functionality in different assays to varying degrees, the generation of functional data quantifying assay performance is essential for understanding the contribution of this association to GDF15 plasma levels and improving the 333 power of MR analyses. Similarly, as our GDF 15 PTV data is based solely on heterozygous carriers,

334 it is possible that the other allele is compensating for the loss and further assessment of the impact 335 of heterozygote GDF15 PTVs on the presence of the protein will be required to validate our 336 findings.

337 Taken together, our study provides a systematic and broad investigation of GDF15 phenotypic and 338 genotypic associations, identifying possible epitope artefacts that could affect the data validity of 339 GDF15 assays and introduce systematic bias in genetic analyses. Taking into account these biases, 340 our genetic analyses did not support a causal association between GDF15 plasma levels and 341 obesity and diabetes in humans. Conversely, we found that increased GDF15 plasma levels may 342 be a consequence of higher BMI. We suggest the strong and wide-ranging associations between 343 GDF15 plasma levels and health outcomes observed predominantly represent secondary effects of 
medRxiv preprint doi: https://doi.org/10.1101/2021.12.15.21267719; this version posted December 16, 2021. The copyright holder for this preprint (which was not certified by peer review) is the author/funder, who has granted medRxiv a license to display the preprint in perpetuity. It is made available under a CC-BY 4.0 International license .

344 the underlying disease process, implicating GDF15 as a stress-induced biomarker. The notion that 345 GDF15 may be merely a predictive marker rather than a causal factor for metabolic diseases draws 346 parallels to CRP in cardiovascular disease. Here, epidemiological studies revealed that elevated 347 plasma CRP levels are consistently associated with increased risks of atherosclerosis and ischemic 348 vascular disease, but Mendelian randomization studies do not show a causal relationship (Davey 349 Smith et al., 2005). Our results do not support GDF15 plasma levels as a causal factor at normal 350 human plasma levels for obesity or its related cardiometabolic diseases. 


\section{Study population and phenotypes}

355 This study was carried out in accordance with the recommendations of the Declaration of Helsinki. 356 All participants of studies have given written informed consent. FINRISK study was approved by 357 the Ethics Committee of Helsinki and Uusimaa Hospital District.

The FINRISK cohort comprises a cross-sectional population survey carried out over a 40-year period from the year 1972 across multiple regions in Finland. The study aimed to assess the risk factors of chronic diseases and health behaviours in a working age population (Borodulin et al., 2018; Vartiainen et al., 2000) and consisted of 6,000-8,800 individuals per survey. Measurement of GDF15 plasma levels using an immunoluminometric assay was included for participants from

363 the 1997 recruitment cohort. Participants were additionally matched to their electronic health 364 records giving access to longitudinal prescription records, death records and diagnosis history. The 365 cohort characteristics are summarized in Supplementary Table S1. In total, 6,610 Finnish individuals from the FINRISK 1997 cohort with available GDF15 plasma concentrations and up

367 to 676 disease outcomes were included in this analysis.

368 Nurse assessment/interview, self-report data and blood samples were all collected at various time 369 points during the study (see Supplementary Materials). A group of clinicians working in the

370 FinnGen consortium constructed 676 disease endpoints combining information from multiple 371 health registries (T et al., 2020). Both ICD8, ICD9 and ICD10 codes were utilized in the disease 372 endpoint definitions. Genotyping was carried out for in 6,538 individuals who were recruited in 373 1997, for more information see Suplementary Materials.

375 The INTERVAL study is a prospective cohort study comprising approximately 50,000 participants 376 nested within a pragmatic randomized trial of blood donors [33]. Between 2012 and 2014, blood 
medRxiv preprint doi: https://doi.org/10.1101/2021.12.15.21267719; this version posted December 16, 2021. The copyright holder for this preprint (which was not certified by peer review) is the author/funder, who has granted medRxiv a license to display the preprint in perpetuity.

It is made available under a CC-BY 4.0 International license .

377 donors aged 18 years and older were recruited at 25 NHSBT (National Health Service Blood and

378 Transplant) donor centres across England (see Supplementary Materials). Informed consent was

379 obtained from all participants and the INTERVAL study was approved by the National Research

380 Ethics Service (11/EE/0538).

381 For the SOMAscan assays, two non-overlapping subcohorts of 2,731 and 831 participants were

382 randomly selected, of which 3,301 participants (2,481 and 820 in the two subcohorts) remained

383 after genetic quality control.

384 For the Olink assay, protein measurements were conducted in an additional subcohort of 4,998

385 INTERVAL participants aged over 50 at baseline. 4,987 samples passed quality control for this

386 panel and were included in the analyses.

387 For information on genotyping in the INTERVAl cohort see Suplementary Materials

\section{UK Biobank}

389 UK Biobank is a population-based cohort consisting of $\sim 500,000$ individuals with participants

390 recruited between 2006-2010 and aged between 40-69. Recruitment and cohort information has

391 been previously described (Sudlow et al., 2015). Electronic health records, self-report

392 questionnaires, diet and lifestyle information and biomarker data is available on this cohort. Here,

393 we utilised body mass index (BMI) and waist-hip-ratio (WHR), which were measured during a

394 nurse assessment, as well as diabetes information. Touchscreen questionnaire diabetic patients

395 were applied in this study rather than ICD10 diagnosed in order to increase patient numbers, given

396 the small subgroup of individuals being examined. Details on the exome sequencing are available

397 in the Supplementary Materials.

\section{Laboratory methods for GDF15 measurement}


medRxiv preprint doi: https://doi.org/10.1101/2021.12.15.21267719; this version posted December 16, 2021. The copyright holder for this preprint (which was not certified by peer review) is the author/funder, who has granted medRxiv a license to display the preprint in perpetuity.

It is made available under a CC-BY 4.0 International license .

400 Blood samples were collected after an advisory 4-hour fast, immediately centrifuged and then

401 stored at $-70^{\circ} \mathrm{C}$ until GDF15 measurement which was undertaken using an immunoluminometric 402 assay (ILMA) with a limit of detection of $24 \mathrm{ng} / \mathrm{L}$ and a linear range from 200 to $50.000 \mathrm{ng} / \mathrm{L}$ 403 (Kempf et al., 2007). The ILMA is technically identical to immunoradiometric assay (IRMA) 404 (Horn, Geldszus, Potter, von zur Muhlen, \& Brabant, 1996) except that the GDF15 detection 405 antibody was labelled with acridinium ester and assay results were quantified in a luminometer 406 (Berthold). ILMA and IRMA use an antibody that binds over a sequence of Ala197-Ile308. GDF40715 concentrations measured with the ILMA and IRMA are very similar [(ILMA 408 concentration/ILMA concentration) $\times 100 \%=97.8 \pm 1.3 \%$ ] and closely correlated 409 ( 2 2 $=0.99 . p<0.001 . n=31$ samples $)(\mathrm{H})$. Head-to-head comparison of IRMA with the clinical 410 'gold standard' Roche assay have been previously conducted and reported GDF15 levels were 411 comparable (Wollert et al., 2017).

\section{INTERVAL}

413 Blood sample collection procedures have been described previously (C. Moore et al., 2014). Blood 414 samples were collected in 6-ml EDTA tubes and transferred at ambient temperature to UK 415 Biocentre (Stockport, UK) for processing. Plasma was extracted by centrifugation into two 0.8-ml 416 plasma aliquots and stored at $-80^{\circ} \mathrm{C}$ before use.

417 The procedures for obtaining protein measurements using the SOMAscan assay have also been 418 described previously (Sun et al., 2018). Briefly, SOMAscan is a multiplexed, aptamer-based 419 approach that was used to measure the relative concentrations of 3,622 plasma proteins or protein 420 complexes using modified aptamers ('SOMAmer reagents', hereafter referred to as SOMAmers). 421 Aliquots of $150 \mu \mathrm{l}$ of plasma from INTERVAL baseline samples were sent on dry ice to 422 SomaLogic Inc. (Boulder, Colorado, US) for protein measurement. Modified single-stranded DNA 423 SOMAmers were used to bind to specific protein targets and these are then quantified using a DNA 424 microarray. Protein concentrations are quantified as relative fluorescent units. Quality control (QC) 425 was completed at the sample and SOMAmer levels. 
medRxiv preprint doi: https://doi.org/10.1101/2021.12.15.21267719; this version posted December 16, 2021. The copyright holder for this preprint (which was not certified by peer review) is the author/funder, who has granted medRxiv a license to display the preprint in perpetuity.

It is made available under a CC-BY 4.0 International license .

426 The Olink assay uses pairs of monoclonal antibodies (or a single polyclonal antibody) to bind each

427 protein target, and then uses proximity extension followed by qPCR to quantify protein abundance.

428 Aliquots of plasma from samples taken from INTERVAL participants at the 2-year follow-up

429 survey were shipped on dry ice to Olink Proteomics (Uppsala, Sweden) for assay. Protein

430 concentrations were recorded as normalised relative protein abundances ('NPX').

\section{Genome-wide association analysis}

$432 \quad$ FINRISK

433 For the FINRISK cohort genome-wide association analyses were performed for 5817 individuals

434 with plasma GDF15 concentrations available. A normal distribution of GDF15 plasma 435 concentrations was achieved through applying an inverse normal transformation.

436 Multidimensional scaling was done for genetic data of both studies using PLINK version 1.07

437 (Purcell et al., 2007). Only good quality autosomal markers passing the following criteria:

438 imputation informativeness $>0.7$, and $\mathrm{MAF}>0.001$, were included in further evaluations.

439 Frequentist test with method 'expected', assuming an additive genetic model, was performed using

440 SNPTEST v2 (Marchini, Howie, Myers, McVean, \& Donnelly, 2007). Results were adjusted for

441 the first five principal components of the genetic data to account for the population stratification

442 and for gender, age and genotyping set. The Quantile-Quantile and Manhattan plots and regional

443 plots were created using R-2.11 to visualize genome-wide association results. The genomic

444 positions indicated throughout this study are based on NCBI human genome build 37.

INTERVAL

446 The GWAS for INTERVAL-SOMAscan has previously been described in detail (Sun et al., 2018).

447 Relative protein abundances were first natural log-transformed within each subcohort. Log448 transformed protein levels were then adjusted in a linear regression for age, sex, duration between 449 blood draw and processing (binary, $\leq 1$ day/ $>1$ day) and the first three principal components of 450 ancestry from multi-dimensional scaling. A normal distribution of the protein residuals from this 451 linear regression was achieved through rank-inverse normal transformation and these were used 452 as phenotypes for association testing. Simple linear regression assuming an additive genetic model 
medRxiv preprint doi: https://doi.org/10.1101/2021.12.15.21267719; this version posted December 16, 2021. The copyright holder for this preprint (which was not certified by peer review) is the author/funder, who has granted medRxiv a license to display the preprint in perpetuity.

It is made available under a CC-BY 4.0 International license .

453 was used to test for genetic associations. Genotype uncertainty was accounted for by carrying out

454 association tests on allelic dosages ('method expected' option) using SNPTEST v2.5.2 [51].

455 For the INTERVAL-Olink GWAS, normalized protein levels ('NPX') were first regressed on age,

456 sex, plate, time from blood draw to processing (in days), and season (categorical: 'Spring',

457 'Summer', 'Autumn', 'Winter'). The residuals from this linear regression were rank-inverse

458 normalized. The rank-inverse normalized residuals were then fitted in a linear regression model

459 adjusted for ancestry by including the first three components of multi-dimensional scaling as

460 covariates. GWAS was conducted using SNPTEST v2.5.2.

\section{$461 \quad$ Fine mapping}

462 Fine mapping was performed using FINEMAP program (Benner et al., 2016). FINEMAP can

463 potentially identify sets of variants with more evidence of being causal than those highlighted by

464 a stepwise conditional analysis. The FINEMAP provides (1) a list of potential causal

465 configurations together with their posterior probabilities and Bayes factors and, (2) for each

466 variant, the posterior probability and Bayes factor of being causal. FINEMAP was applied with

467 its default settings. LD between SNPs for the conditional analysis was combined using the

468 formula: $(\mathrm{N} 1 * \mathrm{LD} 1+\mathrm{N} 2 * \mathrm{LD} 2+\mathrm{N} 3 * \mathrm{LD} 3) /(\mathrm{N} 1+\mathrm{N} 2+\mathrm{N} 3)$, where N represents the number

469 of individuals in the GWAS in each cohort, LD represents the $\mathrm{R}^{2}$ value and 1, 2 and 3 represent

470 the three different cohorts: FINRISK, INTERVAL-SomaScan and INTERVAL-Olink.

472 Meta-analysis

473 Meta-analysis was completed on the chromosome 19 locus around the GDF15 gene in METAL

474 (Willer, Li, \& Abecasis, 2010) using the Inverse-variance Weighted method. A total of 3,799 SNPs

475 were found in common across FINRISK, INTERVAL-SomaScan and INTERVAL-Olink.

\section{Statistical analysis}

477 Association study between GDF15 levels and disease endpoints and quantitative biomarkers 
medRxiv preprint doi: https://doi.org/10.1101/2021.12.15.21267719; this version posted December 16, 2021. The copyright holder for this preprint (which was not certified by peer review) is the author/funder, who has granted medRxiv a license to display the preprint in perpetuity.

It is made available under a CC-BY 4.0 International license .

478 To examine the association of GDF15 with disease endpoints and quantitative biomarkers, logistic

479 and linear regression models were used, respectively. Inverse-variance transformed GDF15 levels

480 were used in the analyses due to right-skewed distribution. Association of GDF15 with disease

481 endpoints and quantitative biomarkers were examined in 1) age- and sex 2) age, sex and BMI 3)

482 age, sex and smoking -adjusted models. Analyses using linear- and logistic regression models were

483 performed using R2.11 (see URLs). False discovery rate (FDR) was applied to test for multiple

484 test correction.

Survival analysis

486 All analyses were performed in $\mathrm{R}$ version 3.4.0. Cox proportional hazard regression model was

487 conducted to identify predictors of outcomes during 10 years. The survival curves for a Cox

488 proportional hazards model were used to illustrate the timing of the death, type 2 diabetes and

489 CVD events during 10 years in relation to GDF15 quartiles and statistical assessment between

490 upper quartile and other quartiles was preformed using cox proportional hazard regression model.

491 To inspect the validity of the cox-model, the test of the proportional hazards assumption for a Cox

492 regression model was used. Hosmer-Lemeshow Goodness of Fit (GOF) test was used to determine

493 whether models were calibrated with similar expected and observed event rates in both low- and

494 high-risk individuals.

Wilcoxon test for prevalent and incident diabetes

496 Wilcoxon rank sum test (Mann-Whitney U test) was performed, in R using function "wilcox.test" 497 from stats package, to test whether the distributions of incident type 2 diabetes case group, 498 prevalent type 2 diabetes case group and control group were systematically different from one 499 another.

502 We applied MR (Bowden et al., 2015) to explore causality of GDF15 with BMI, WHR, glucose, 503 type 2 diabetes, HDL cholesterol and BMD. We additionally explored these relationship in reverse; 
504 with GDF15 as an outcome and other traits as the exposure. GWAS summary statistics for GDF15 505 were taken from the conditional meta-analysis of FINRISK and INTERVAL for the forward MR 506 and from FINRISK only for the reverse MR. GWAS in INTERVAL being completed on

507 chromosome 19 only whereas GWAS in FINRISK were completed on all chromosomes. Summary 508 statistics for the other traits were obtained from large public data resources: BMI $(n=590,827)$ 509 (Yengo L et al., 2018), WHR ( $\mathrm{n}=485,486)$ (Shungin et al., 2015), glucose $(\mathrm{n}=314,916)$ (Neale, 510 2018), type 2 diabetes ( $\mathrm{n}$ cases=74,124, $\mathrm{n}$ controls=824,006) (Mahajan et al., 2018), HDL 511 cholesterol $(n=315,133)$ (Neale, 2018) and BMD $(n=426,824)$ (Morris et al., 2019). For BMI, MR 512 with GDF15 as the exposure was applied using summary statistics from UK Biobank only $513(n=361,194)$ as the LD clumped variants were not available in the larger meta-analysis, that was 514 utilised for reverse MR. We utilised LD clumping to identify independent genetic variants in 515 summary statistics and applied these as genetic instruments in MR analyses. MR analysis was run 516 in R (version 4.0.2) using the package 'MendelianRandomization'. The inverse variance weighted 517 method (IVW) from this package was applied to test for causality and a sensitivity analysis using 518 MR-Egger to testing for horizontal pleiotropy. A finding of significant causality is indicated with 519 the IVW $p$-value and a significant MR-Egger intercept $p$-value indicates a finding of horizontal 520 pleiotropy. MR-PRESSO (Mendelian randomization pleiotropy residual sum and outlier) 521 (Verbanck et al., 2018) was additionally applied as a further sensitivity analysis to test for 522 horizontal pleiotropy and was run in $\mathrm{R}$ using the 'MRPRESSO' package. The Global $p$-value 523 indicates a significant finding of horizontal pleiotropy which instigates removal of outliers from 524 the analysis. MR-PRESSO then re-runs IVW testing and gives a significant distortion $p$-value to 525 indicate if the removal of outliers reduced the horizontal pleiotropy found in the analysis.

\section{GDF15 PTV analysis}

\section{Exome data}

528 Individuals with GDF15 PTVs were identified by extracting variants annotated as protein 529 truncating variants (including exon loss variants, frameshift variants, start lost, stop gained, stop 530 lost, splice acceptor variants, splice donor variant, rare amino acid variant, transcript ablation, gene 531 fusion and bidirectional gene fusion). Supplementary Table S19 demonstrates the frequency of 
532 LOF variants in each ancestry. From the individuals that did not carry GDF 15 PTV variants 20,000

533 males and 20,000 females were randomly extracted as controls.

535 Analysis was completed in R (version 3.2.4) using "wilcox.test" and models compared BMI, WHR

536 (in males and females separately), diabetic status (self-reported), BMD and HDL in GDF15 PTV 537 carriers and non-carriers.

Acknowledgements: We thank the participants and investigators in the UK Biobank study who made this work possible (Resource Application Number 26041). We thank the UK Biobank Exome Sequencing Consortium (UKB-ESC) members AbbVie, Alnylam Pharmaceuticals, AstraZeneca, Biogen, Bristol-Myers Squibb, Pfizer, Regeneron and Takeda for funding the generation of the data and Regeneron Genetics Center for completing the sequencing and initial quality control of the exome sequencing data. We thank the AstraZeneca Centre for Genomics Research Analytics and Informatics team for processing and analysis of sequencing data.

Participants in the INTERVAL randomised controlled trial were recruited with the active collaboration of NHS Blood and Transplant England (www.nhsbt.nhs.uk), which has supported field work and other elements of the trial. DNA extraction and genotyping was co-funded by the National Institute for Health Research (NIHR), the NIHR BioResource (http://bioresource.nihr.ac.uk) and the NIHR Cambridge Biomedical Research Centre (BRC1215-20014) [*]. SomaLogic assays were funded by Merck and the NIHR Cambridge BRC (BRC-1215-20014) [*]. The academic coordinating centre for INTERVAL was supported by core funding from: NIHR Blood and Transplant Research Unit in Donor Health and Genomics (NIHR BTRU-2014-10024), UK Medical Research Council (MR/L003120/1), British Heart Foundation (SP/09/002; RG/13/13/30194; RG/18/13/33946) and the NIHR Cambridge BRC (BRC-1215-20014) [*]. A complete list of the investigators and contributors to the INTERVAL trial is provided in reference [**]. The academic coordinating centre would like to thank blood donor centre staff and blood donors for participating in the INTERVAL trial. 
This work was supported by Health Data Research UK, which is funded by the UK Medical Research Council, Engineering and Physical Sciences Research Council, Economic and Social Research Council, Department of Health and Social Care (England), Chief Scientist Office of the Scottish Government Health and Social Care Directorates, Health and Social Care Research and Development Division (Welsh Government), Public Health Agency (Northern Ireland), British Heart Foundation and Wellcome.

This work was conducted as part of an alliance between the University of Cambridge and the AstraZeneca Centre for Genomics Research (AZ Ref: 10033507).

The Genotype-Tissue Expression (GTEx) Project was supported by the Common Fund of the Office of the Director of the National Institutes of Health, and by NCI, NHGRI, NHLBI, NIDA, NIMH, and NINDS. The data used for the analyses described in this manuscript were obtained from the GTEx Portal on 08/12/2021.

*The views expressed are those of the author(s) and not necessarily those of the NIHR or the Department of Health and Social Care.

**Di Angelantonio E, Thompson SG, Kaptoge SK, Moore C, Walker M, Armitage J, Ouwehand WH, Roberts DJ, Danesh J, INTERVAL Trial Group. Efficiency and safety of varying the frequency of whole blood donation (INTERVAL): a randomised trial of 45000 donors. Lancet. 2017 Nov 25;390(10110):2360-2371.

Funding: Rachel Ong is co-funded by the NIHR Cambridge Biomedical Research Centre (BRC1215-20014) [*]. VS has been supported by the Finnish Foundation for Cardiovascular Research.

\section{Author contributions:}

Competing interests: EMW, RM, DSP and AM are employees of AstraZeneca. RMYO is currently an employee of GlaxoSmithKline (although was not when this work was carried out). AB reports grants outside of this work from Biogen, BioMarin, Bioverativ, Merck, Novartis, Pfizer and Sanofi and personal fees from Novartis. VS has received honoraria from Novo Nordisk and Sanofi for consulting. He also has ongoing research collaboration with Bayer Ltd (All outside this work). 
medRxiv preprint doi: https://doi.org/10.1101/2021.12.15.21267719; this version posted December 16, 2021. The copyright holder for this preprint (which was not certified by peer review) is the author/funder, who has granted medRxiv a license to display the preprint in perpetuity.

It is made available under a CC-BY 4.0 International license . 


\section{REFERENCES}

Adela, R., \& Banerjee, S. K. (2015). GDF-15 as a Target and Biomarker for Diabetes and Cardiovascular Diseases: A Translational Prospective. J Diabetes Res, 2015, 490842. doi:10.1155/2015/490842

Akbari, P., Gilani, A., Sosina, O., Kosmicki, J. A., Khrimian, L., Fang, Y. Y., . . Lotta, L. A. (2021). Sequencing of 640,000 exomes identifies GPR75 variants associated with protection from obesity. Science, 373(6550). doi:10.1126/science.abf8683

Bonaca, M. P., Morrow, D. A., Braunwald, E., Cannon, C. P., Jiang, S., Breher, S., ... Wollert, K. C. (2011). Growth differentiation factor-15 and risk of recurrent events in patients stabilized after acute coronary syndrome: observations from PROVE IT-TIMI 22. Arterioscler Thromb Vasc Biol, 31(1), 203-210. doi:10.1161/ATVBAHA.110.213512

Bootcov, M. R., Bauskin, A. R., Valenzuela, S. M., Moore, A. G., Bansal, M., He, X. Y., .. . Breit, S. N. (1997). MIC-1, a novel macrophage inhibitory cytokine, is a divergent member of the TGF-beta superfamily. Proc Natl Acad Sci U S A, 94(21), 11514-11519. doi:10.1073/pnas.94.21.11514

Borner, T., Shaulson, E. D., Ghidewon, M. Y., Barnett, A. B., Horn, C. C., Doyle, R. P., ... De Jonghe, B. C. (2020). GDF15 Induces Anorexia through Nausea and Emesis. Cell Metab, 31(2), 351-362 e355. doi:10.1016/j.cmet.2019.12.004

Borner, T., Wald, H. S., Ghidewon, M. Y., Zhang, B., Wu, Z., De Jonghe, B. C., . . Grill, H. J. (2020). GDF15 Induces an Aversive Visceral Malaise State that Drives Anorexia and Weight Loss. Cell Rep, 31(3), 107543. doi:10.1016/j.celrep.2020.107543

Borodulin, K., Tolonen, H., Jousilahti, P., Jula, A., Juolevi, A., Koskinen, S., . . Vartiainen, E. (2018). Cohort Profile: The National FINRISK Study. Int J Epidemiol, 47(3), 696-696i. doi:10.1093/ije/dyx239

Bowden, J., Davey Smith, G., \& Burgess, S. (2015). Mendelian randomization with invalid instruments: effect estimation and bias detection through Egger regression. Int $J$ Epidemiol, 44(2), 512-525. doi:10.1093/ije/dyv080

Brown, D. A., Breit, S. N., Buring, J., Fairlie, W. D., Bauskin, A. R., Liu, T., \& Ridker, P. M. (2002). Concentration in plasma of macrophage inhibitory cytokine-1 and risk of cardiovascular events in women: a nested case-control study. Lancet, 359(9324), 21592163. doi:10.1016/S0140-6736(02)09093-1

Brown, D. A., Moore, J., Johnen, H., Smeets, T. J., Bauskin, A. R., Kuffner, T., . . Breit, S. N. (2007). Serum macrophage inhibitory cytokine 1 in rheumatoid arthritis: a potential marker of erosive joint destruction. Arthritis Rheum, 56(3), 753-764. doi:10.1002/art.22410

Cheung, C. L., Tan, K. C. B., Au, P. C. M., Li, G. H. Y., \& Cheung, B. M. Y. (2019). Evaluation of GDF15 as a therapeutic target of cardiometabolic diseases in human: A Mendelian randomization study. EBioMedicine, 41, 85-90. doi:10.1016/j.ebiom.2019.02.021

Coll, A. P., Chen, M., Taskar, P., Rimmington, D., Patel, S., Tadross, J. A., . . O'Rahilly, S. (2020). GDF15 mediates the effects of metformin on body weight and energy balance. Nature, 578(7795), 444-448. doi:10.1038/s41586-019-1911-y

Daniels, L. B., Clopton, P., Laughlin, G. A., Maisel, A. S., \& Barrett-Connor, E. (2011). Growthdifferentiation factor-15 is a robust, independent predictor of 11-year mortality risk in community-dwelling older adults: the Rancho Bernardo Study. Circulation, 123(19), 2101-2110. doi:10.1161/CIRCULATIONAHA.110.979740 
Davey Smith, G., Lawlor, D. A., Harbord, R., Timpson, N., Rumley, A., Lowe, G. D., .. . Ebrahim, S. (2005). Association of C-reactive protein with blood pressure and hypertension: life course confounding and mendelian randomization tests of causality. Arterioscler Thromb Vasc Biol, 25(5), 1051-1056. doi:10.1161/01.ATV.0000160351.95181.d0

Day, E. A., Ford, R. J., Smith, B. K., Mohammadi-Shemirani, P., Morrow, M. R., Gutgesell, R. M., . . Steinberg, G. R. (2019). Metformin-induced increases in GDF15 are important for suppressing appetite and promoting weight loss. Nat Metab, 1(12), 1202-1208. doi:10.1038/s42255-019-0146-4

Emmerson, P. J., Duffin, K. L., Chintharlapalli, S., \& Wu, X. (2018). GDF15 and Growth Control. Front Physiol, 9, 1712. doi:10.3389/fphys.2018.01712

Emmerson, P. J., Wang, F., Du, Y., Liu, Q., Pickard, R. T., Gonciarz, M. D., . . Wu, X. (2017). The metabolic effects of GDF15 are mediated by the orphan receptor GFRAL. Nat Med, 23(10), 1215-1219. doi:10.1038/nm.4393

Fairlie, W. D., Russell, P. K., Wu, W. M., Moore, A. G., Zhang, H. P., Brown, P. K., . . Breit, S. N. (2001). Epitope mapping of the transforming growth factor-beta superfamily protein, macrophage inhibitory cytokine-1 (MIC-1): identification of at least five distinct epitope specificities. Biochemistry, 40(1), 65-73. doi:10.1021/bi001064p

Fejzo, M. S., Arzy, D., Tian, R., MacGibbon, K. W., \& Mullin, P. M. (2018). Evidence GDF15 Plays a Role in Familial and Recurrent Hyperemesis Gravidarum. Geburtshilfe Frauenheilkd, 78(9), 866-870. doi:10.1055/a-0661-0287

Fejzo, M. S., Sazonova, O. V., Sathirapongsasuti, J. F., Hallgrimsdottir, I. B., Vacic, V., MacGibbon, K. W., . . . andMe Research, T. (2018). Placenta and appetite genes GDF15 and IGFBP7 are associated with hyperemesis gravidarum. Nat Commun, 9(1), 1178. doi:10.1038/s41467-018-03258-0

Folkersen, L., Gustafsson, S., Wang, Q., Hansen, D. H., Hedman, A. K., Schork, A., . . . Malarstig, A. (2020). Genomic and drug target evaluation of 90 cardiovascular proteins in 30,931 individuals. Nat Metab, 2(10), 1135-1148. doi:10.1038/s42255-020-00287-2

H, T. Dissertation.

Ho, J. E., Mahajan, A., Chen, M. H., Larson, M. G., McCabe, E. L., Ghorbani, A., ... Wang, T. J. (2012). Clinical and genetic correlates of growth differentiation factor 15 in the community. Clin Chem, 58(11), 1582-1591. doi:10.1373/clinchem.2012.190322

Holmes, M. V., Lange, L. A., Palmer, T., Lanktree, M. B., North, K. E., Almoguera, B., . . Keating, B. J. (2014). Causal effects of body mass index on cardiometabolic traits and events: a Mendelian randomization analysis. Am J Hum Genet, 94(2), 198-208. doi:10.1016/j.ajhg.2013.12.014

Horn, R., Geldszus, R., Potter, E., von zur Muhlen, A., \& Brabant, G. (1996). Radioimmunoassay for the detection of leptin in human serum. Exp Clin Endocrinol Diabetes, 104(6), 454-458. doi:10.1055/s-0029-1211484

Hsu, J. Y., Crawley, S., Chen, M., Ayupova, D. A., Lindhout, D. A., Higbee, J., . . Allan, B. B. (2017). Non-homeostatic body weight regulation through a brainstem-restricted receptor for GDF15. Nature, 550(7675), 255-259. doi:10.1038/nature24042

Jackson, C. E., Haig, C., Welsh, P., Dalzell, J. R., Tsorlalis, I. K., McConnachie, A., . . . McMurray, J. J. (2016). The incremental prognostic and clinical value of multiple novel biomarkers in heart failure. Eur J Heart Fail, 18(12), 1491-1498. doi:10.1002/ejhf.543 
Jammah, A. A. (2015). Endocrine and metabolic complications after bariatric surgery. Saudi J Gastroenterol, 21(5), 269-277. doi:10.4103/1319-3767.164183

Jiang, J., Thalamuthu, A., Ho, J. E., Mahajan, A., Ek, W. E., Brown, D. A., . . Mather, K. A. (2018). A Meta-Analysis of Genome-Wide Association Studies of Growth Differentiation Factor-15 Concentration in Blood. Front Genet, 9, 97. doi:10.3389/fgene.2018.00097

Johnen, H., Lin, S., Kuffner, T., Brown, D. A., Tsai, V. W., Bauskin, A. R., . . Breit, S. N. (2007). Tumor-induced anorexia and weight loss are mediated by the TGF-beta superfamily cytokine MIC-1. Nat Med, 13(11), 1333-1340. doi:10.1038/nm1677

Kempf, T., Eden, M., Strelau, J., Naguib, M., Willenbockel, C., Tongers, J., . . Wollert, K. C. (2006). The transforming growth factor-beta superfamily member growth-differentiation factor-15 protects the heart from ischemia/reperfusion injury. Circ Res, 98(3), 351-360. doi:10.1161/01.RES.0000202805.73038.48

Kempf, T., Horn-Wichmann, R., Brabant, G., Peter, T., Allhoff, T., Klein, G., .. . Wollert, K. C. (2007). Circulating concentrations of growth-differentiation factor 15 in apparently healthy elderly individuals and patients with chronic heart failure as assessed by a new immunoradiometric sandwich assay. Clin Chem, 53(2), 284-291. doi:10.1373/clinchem.2006.076828

Khan, S. Q., Ng, K., Dhillon, O., Kelly, D., Quinn, P., Squire, I. B., . . Ng, L. L. (2009). Growth differentiation factor-15 as a prognostic marker in patients with acute myocardial infarction. Eur Heart J, 30(9), 1057-1065. doi:10.1093/eurheartj/ehn600

Lind, L., Wallentin, L., Kempf, T., Tapken, H., Quint, A., Lindahl, B., . . Wollert, K. C. (2009). Growth-differentiation factor-15 is an independent marker of cardiovascular dysfunction and disease in the elderly: results from the Prospective Investigation of the Vasculature in Uppsala Seniors (PIVUS) Study. Eur Heart J, 30(19), 2346-2353. doi:10.1093/eurheartj/ehp261

Lockhart, S. M., Saudek, V., \& O'Rahilly, S. (2020). GDF15: A hormone conveying somatic distress to the brain. Endocr Rev. doi:10.1210/endrev/bnaa007

Madonna, R., Cevik, C., Nasser, M., \& De Caterina, R. (2012). Hepatocyte growth factor: molecular biomarker and player in cardioprotection and cardiovascular regeneration. Thromb Haemost, 107(4), 656-661. doi:10.1160/TH11-10-0711

Mahajan, A., Taliun, D., Thurner, M., Robertson, N. R., Torres, J. M., Rayner, N. W., . . . McCarthy, M. I. (2018). Fine-mapping type 2 diabetes loci to single-variant resolution using high-density imputation and islet-specific epigenome maps. Nat Genet, 50(11), 1505-1513. doi:10.1038/s41588-018-0241-6

Marchini, J., Howie, B., Myers, S., McVean, G., \& Donnelly, P. (2007). A new multipoint method for genome-wide association studies by imputation of genotypes. Nat Genet, 39(7), 906-913. doi:10.1038/ng2088

Matsumoto, K., Umitsu, M., De Silva, D. M., Roy, A., \& Bottaro, D. P. (2017). Hepatocyte growth factor/MET in cancer progression and biomarker discovery. Cancer Sci, 108(3), 296-307. doi:10.1111/cas.13156

Mesureur, L., \& Arvanitakis, M. (2017). Metabolic and nutritional complications of bariatric surgery : a review. Acta Gastroenterol Belg, 80(4), 515-525.

Miller, V. M., Redfield, M. M., \& McConnell, J. P. (2007). Use of BNP and CRP as biomarkers in assessing cardiovascular disease: diagnosis versus risk. Curr Vasc Pharmacol, 5(1), 15-25. doi:10.2174/157016107779317251 
Moore, A. G., Brown, D. A., Fairlie, W. D., Bauskin, A. R., Brown, P. K., Munier, M. L., .. . Breit, S. N. (2000). The transforming growth factor-ss superfamily cytokine macrophage inhibitory cytokine- 1 is present in high concentrations in the serum of pregnant women. $J$ Clin Endocrinol Metab, 85(12), 4781-4788. doi:10.1210/jcem.85.12.7007

Moore, C., Sambrook, J., Walker, M., Tolkien, Z., Kaptoge, S., Allen, D., . . Danesh, J. (2014). The INTERVAL trial to determine whether intervals between blood donations can be safely and acceptably decreased to optimise blood supply: study protocol for a randomised controlled trial. Trials, 15, 363. doi:10.1186/1745-6215-15-363

Morris, J. A., Kemp, J. P., Youlten, S. E., Laurent, L., Logan, J. G., Chai, R. C., . . Richards, J. B. (2019). An atlas of genetic influences on osteoporosis in humans and mice. Nat Genet, 51(2), 258-266. doi:10.1038/s41588-018-0302-x

Mullican, S. E., Lin-Schmidt, X., Chin, C. N., Chavez, J. A., Furman, J. L., Armstrong, A. A., ... Rangwala, S. M. (2017). GFRAL is the receptor for GDF15 and the ligand promotes weight loss in mice and nonhuman primates. Nat Med, 23(10), 1150-1157. doi:10.1038/nm.4392

Nair, V., Robinson-Cohen, C., Smith, M. R., Bellovich, K. A., Bhat, Z. Y., Bobadilla, M., .. . Bansal, N. (2017). Growth Differentiation Factor-15 and Risk of CKD Progression. $J$ Am Soc Nephrol, 28(7), 2233-2240. doi:10.1681/ASN.2016080919

Neale, B. (2018). GWAS results.

O'Rahilly, S. (2017). GDF15-From Biomarker to Allostatic Hormone. Cell Metab, 26(6), 807808. doi:10.1016/j.cmet.2017.10.017

Organisaton., W. H. Global Health Observatory (GBO) data: Obesity.

Patel, S., Alvarez-Guaita, A., Melvin, A., Rimmington, D., Dattilo, A., Miedzybrodzka, E. L., . . O'Rahilly, S. (2019). GDF15 Provides an Endocrine Signal of Nutritional Stress in Mice and Humans. Cell Metab, 29(3), 707-718 e708. doi:10.1016/j.cmet.2018.12.016

Peacock, W. F. (2014). Novel biomarkers in acute heart failure: MR-pro-adrenomedullin. Clin Chem Lab Med, 52(10), 1433-1435. doi:10.1515/cclm-2014-0222

Pietzner, M., Wheeler, E., Carrasco-Zanini, J., Raffler, J., Kerrison, N. D., Oerton, E., .. . Langenberg, C. (2020). Genetic architecture of host proteins interacting with SARSCoV-2. BioRxiv, doi: https://doi.org/10.1101/2020.1107.1101.182709doi.

Purcell, S., Neale, B., Todd-Brown, K., Thomas, L., Ferreira, M. A., Bender, D., . . Sham, P. C. (2007). PLINK: a tool set for whole-genome association and population-based linkage analyses. Am J Hum Genet, 81(3), 559-575. doi:10.1086/519795

Rohatgi, A., Patel, P., Das, S. R., Ayers, C. R., Khera, A., Martinez-Rumayor, A., ... de Lemos, J. A. (2012). Association of growth differentiation factor-15 with coronary atherosclerosis and mortality in a young, multiethnic population: observations from the Dallas Heart Study. Clin Chem, 58(1), 172-182. doi:10.1373/clinchem.2011.171926

Shungin, D., Winkler, T. W., Croteau-Chonka, D. C., Ferreira, T., Locke, A. E., Magi, R., .. . Mohlke, K. L. (2015). New genetic loci link adipose and insulin biology to body fat distribution. Nature, 518(7538), 187-196. doi:10.1038/nature14132

Sudlow, C., Gallacher, J., Allen, N., Beral, V., Burton, P., Danesh, J., . . Collins, R. (2015). UK biobank: an open access resource for identifying the causes of a wide range of complex diseases of middle and old age. PLoS Med, 12(3), e1001779. doi:10.1371/journal.pmed.1001779 
Sun, B. B., Maranville, J. C., Peters, J. E., Stacey, D., Staley, J. R., Blackshaw, J., . . Butterworth, A. S. (2018). Genomic atlas of the human plasma proteome. Nature, 558(7708), 73-79. doi:10.1038/s41586-018-0175-2

T, K., Lahtela E, Havulinna AS, \& Consortium., F. (2020). https://www.finngen.fi/en/researchers/clinical-endpoints.

Tran, T., Yang, J., Gardner, J., \& Xiong, Y. (2018). GDF15 deficiency promotes high fat dietinduced obesity in mice. PLoS One, 13(8), e0201584. doi:10.1371/journal.pone.0201584

Tsai, V. W., Macia, L., Feinle-Bisset, C., Manandhar, R., Astrup, A., Raben, A., . . Breit, S. N. (2015). Serum Levels of Human MIC-1/GDF15 Vary in a Diurnal Pattern, Do Not Display a Profile Suggestive of a Satiety Factor and Are Related to BMI. PLoS One, 10(7), e0133362. doi:10.1371/journal.pone.0133362

Tsai, V. W. W., Husaini, Y., Sainsbury, A., Brown, D. A., \& Breit, S. N. (2018). The MIC1/GDF15-GFRAL Pathway in Energy Homeostasis: Implications for Obesity, Cachexia, and Other Associated Diseases. Cell Metab, 28(3), 353-368. doi:10.1016/j.cmet.2018.07.018

Vartiainen, E., Jousilahti, P., Alfthan, G., Sundvall, J., Pietinen, P., \& Puska, P. (2000). Cardiovascular risk factor changes in Finland, 1972-1997. Int J Epidemiol, 29(1), 49-56.

Verbanck, M., Chen, C. Y., Neale, B., \& Do, R. (2018). Detection of widespread horizontal pleiotropy in causal relationships inferred from Mendelian randomization between complex traits and diseases. Nat Genet, 50(5), 693-698. doi:10.1038/s41588-018-0099-7

Vila, G., Riedl, M., Anderwald, C., Resl, M., Handisurya, A., Clodi, M., .. . Luger, A. (2011). The relationship between insulin resistance and the cardiovascular biomarker growth differentiation factor-15 in obese patients. Clin Chem, 57(2), 309-316. doi:10.1373/clinchem.2010.153726

Wang, D., Day, E. A., Townsend, L. K., Djordjevic, D., Jorgensen, S. B., \& Steinberg, G. R. (2021). GDF15: emerging biology and therapeutic applications for obesity and cardiometabolic disease. Nat Rev Endocrinol, 17(10), 592-607. doi:10.1038/s41574-02100529-7

Wiklund, F. E., Bennet, A. M., Magnusson, P. K., Eriksson, U. K., Lindmark, F., Wu, L., . . . Brown, D. A. (2010). Macrophage inhibitory cytokine-1 (MIC-1/GDF15): a new marker of all-cause mortality. Aging Cell, 9(6), 1057-1064. doi:10.1111/j.14749726.2010.00629.x

Wilding, J. P. H., Batterham, R. L., Calanna, S., Davies, M., Van Gaal, L. F., Lingvay, I., .. . Group, S. S. (2021). Once-Weekly Semaglutide in Adults with Overweight or Obesity. $N$ Engl J Med, 384(11), 989. doi:10.1056/NEJMoa2032183

Willer, C. J., Li, Y., \& Abecasis, G. R. (2010). METAL: fast and efficient meta-analysis of genomewide association scans. Bioinformatics, 26(17), 2190-2191. doi:10.1093/bioinformatics/btq340

Wollert, K. C., Kempf, T., Giannitsis, E., Bertsch, T., Braun, S. L., Maier, H., . . Christenson, R. H. (2017). An Automated Assay for Growth Differentiation Factor 15. J Appl Lab Med, 1(5), 510-521. doi:10.1373/jalm.2016.022376

Wollert, K. C., Kempf, T., Lagerqvist, B., Lindahl, B., Olofsson, S., Allhoff, T., ... Wallentin, L. (2007). Growth differentiation factor 15 for risk stratification and selection of an invasive treatment strategy in non ST-elevation acute coronary syndrome. Circulation, 116(14), 1540-1548. doi:10.1161/CIRCULATIONAHA.107.697714 
Xiong, Y., Walker, K., Min, X., Hale, C., Tran, T., Komorowski, R., . . Veniant, M. M. (2017). Long-acting MIC-1/GDF15 molecules to treat obesity: Evidence from mice to monkeys. Sci Transl Med, 9(412). doi:10.1126/scitranslmed.aan8732

Yang, L., Chang, C. C., Sun, Z., Madsen, D., Zhu, H., Padkjaer, S. B., . . Jorgensen, S. B. (2017). GFRAL is the receptor for GDF15 and is required for the anti-obesity effects of the ligand. Nat Med, 23(10), 1158-1166. doi:10.1038/nm.4394

Yengo L, Sidorenko J, Kemper KE, Zheng Z, Wood AR, Weedon MN, . . Consortium, G. (2018). Meta-analysis of genome-wide association studies for height and body mass index in $~ 700,000$ individuals of European ancestry. BioRxiv, doi: https://doi.org/10.1101/274654

Yumuk, V., Tsigos, C., Fried, M., Schindler, K., Busetto, L., Micic, D., . . Obesity., O. M. T. F. o. t. E. A. f. t. S. o. (2016). European Guidelines for Obesity Management in Adults Obes Facts, 9(1), 64. doi:10.1159/000444869

Zimmers, T. A., Jin, X., Hsiao, E. C., McGrath, S. A., Esquela, A. F., \& Koniaris, L. G. (2005). Growth differentiation factor-15/macrophage inhibitory cytokine-1 induction after kidney and lung injury. Shock, 23(6), 543-548. 
Tables

Table 1. Disease endpoints associated $\left(p_{\mathrm{FDR}}<1 \times 10^{-5}\right)$ with GDF15 plasma levels in FINRISK.

\begin{tabular}{lccc}
\hline Disease Endpoint & Cases / Controls & OR (95\% CI) & $p_{\text {FDR }}$ \\
\hline All-cause mortality & $1057 / 5481$ & $1.79(1.68-1.90)$ & $7.5 \times 10^{-24}$ \\
Death due to cardiac causes & $471 / 6067$ & $1.76(1.61-1.90)$ & $3.0 \times 10^{-11}$ \\
Atherosclerosis, excluding cerebral, coronary and PAD & $379 / 6159$ & $1.67(1.51-1.82)$ & $3.2 \times 10^{-8}$ \\
Diabetes mellitus type 2 & $567 / 5971$ & $1.48(1.36-1.60)$ & $3.2 \times 10^{-8}$ \\
Diabetes mellitus & $592 / 5946$ & $1.44(1.33-1.56)$ & $9.8 \times 10^{-8}$ \\
Diseases of arteries, arterioles and capillaries & $505 / 6033$ & $1.48(1.35-1.61)$ & $3.6 \times 10^{-7}$ \\
Other chronic obstructive pulmonary disease & $221 / 6317$ & $1.84(1.63-2.04)$ & $5.7 \times 10^{-7}$ \\
Chronic obstructive pulmonary disease & $235 / 6303$ & $1.77(1.57-1.97)$ & $9.6 \times 10^{-7}$ \\
Pneumonia (excl. viral and due to other infectious & $779 / 5759$ & $1.34(1.24-1.44)$ & $9.6 \times 10^{-7}$ \\
organisms not elsewhere classified) & $485 / 6053$ & $1.44(1.31-1.57)$ & $1.2 \times 10^{-6}$ \\
Type 2 diabetes without complications & $789 / 5749$ & $1.33(1.23-1.43)$ & $1.9 \times 10^{-6}$ \\
All pneumonia & $66 / 6472$ & $2.46(2.14-2.79)$ & $4.4 \times 10^{-6}$ \\
Chronic kidney disease & $833 / 5795$ & $1.30(1.21-1.40)$ & $4.4 \times 10^{-6}$ \\
Influenza and pneumonia & $35 / 6503$ & $2.97(2.57-3.38)$ & $8.1 \times 10^{-6}$ \\
Type 2 diabetes with renal complications & $209 / 6329$ & $1.67(1.47-1.86)$ & $9.2 \times 10^{-6}$ \\
Sequelae of cerebrovascular disease & $56 / 6482$ & $2.26(1.95-2.57)$ & $9.2 \times 10^{-6}$ \\
Alcoholic liver disease & & &
\end{tabular}

Results are adjusted for age, gender, smoking and BMI. Abbreviations: OR, odds ratio; CI, confidence interval; COPD, chronic obstructive pulmonary disease; PAD, peripheral artery disease; SAH, subarachnoid haemorrhage. ICD codes for these disease endpoints have been published (T et al., 2020). 
medRxiv preprint doi: https://doi.org/10.1101/2021.12.15.21267719; this version posted December 16, 2021. The copyright holder for this preprint (which was not certified by peer review) is the author/funder, who has granted medRxiv a license to display the preprint in perpetuity.

It is made available under a CC-BY 4.0 International license .

Table 2. Meta-analysis of GDF15 GWAS conditioned on rs1058587 in FINRISK and INTERVAL.

\begin{tabular}{|c|c|c|c|c|c|c|c|c|c|c|c|c|}
\hline \multirow[b]{2}{*}{ SNPs } & \multirow[b]{2}{*}{$\begin{array}{c}\text { LD } \\
\text { block }\end{array}$} & \multirow[b]{2}{*}{ EA/OA } & \multicolumn{2}{|c|}{ FINRISK } & \multicolumn{2}{|c|}{$\begin{array}{l}\text { INTERVAL- } \\
\text { SomaScan }\end{array}$} & \multicolumn{2}{|c|}{$\begin{array}{l}\text { INTERVAL- } \\
\text { Olink }\end{array}$} & \multicolumn{4}{|c|}{ Meta-analysis } \\
\hline & & & beta & $p$-value & beta & $p$-value & beta & $p$-value & beta & $p$-value & $\begin{array}{c}\text { Heterogeneity } \\
\mathbf{I}^{\mathbf{2}} \\
\end{array}$ & $\begin{array}{c}\text { Heterogeneity } \\
p \text {-value }\end{array}$ \\
\hline rs16982345 & 1 & $\mathrm{~A} / \mathrm{G}$ & -0.28 & 0.55 & 0.30 & 0.18 & 0.01 & 0.72 & 0.01 & 0.64 & 4.2 & 0.35 \\
\hline rs1058587 & 1 & $\mathrm{G} / \mathrm{C}$ & - & - & - & - & 0.01 & 0.77 & - & - & - & - \\
\hline rs3787023 & 1 & $\mathrm{~A} / \mathrm{G}$ & 0.06 & 0.0011 & -0.011 & 0.72 & 0.04 & 0.072 & 0.04 & 0.0017 & 51.4 & 0.13 \\
\hline rs 1055150 & 1 & $\mathrm{G} / \mathrm{C}$ & 0.06 & 0.0012 & -0.017 & 0.56 & 0.04 & 0.080 & 0.04 & 0.0025 & 58.5 & 0.090 \\
\hline rs1059369 & 1 & $\mathrm{~A} / \mathrm{T}$ & 0.06 & 0.0010 & -0.018 & 0.54 & 0.04 & 0.078 & 0.04 & 0.0024 & 60.2 & 0.081 \\
\hline rs 1054221 & 2 & $\mathrm{C} / \mathrm{T}$ & 0.38 & $\underset{37}{3.4 \times 10^{-}}$ & 0.62 & $7.8 \times 10^{-83}$ & 0.52 & $\underset{74}{9.4 \times 10^{-}}$ & 0.50 & $\begin{array}{c}2.4 \times 10^{-} \\
186\end{array}$ & 93.4 & $2.9 \times 10^{-7}$ \\
\hline rs 1227734 & 2 & $\mathrm{~T} / \mathrm{C}$ & 0.38 & $\underset{37}{3.9 \times 10^{-}}$ & 0.62 & $1.8 \times 10^{-83}$ & 0.51 & $\underset{74}{7.1 \times 10^{-}}$ & 0.50 & $\underset{187}{2.5 \times 10^{-}}$ & 93.1 & $5.4 \times 10^{-7}$ \\
\hline rs189593084 & 3 & $\mathrm{~A} / \mathrm{C}$ & -0.33 & $\underset{14}{8.4 \times 10^{-}}$ & -0.61 & 0.011 & -0.47 & 0.0053 & -0.35 & $\begin{array}{c}1.3 \times 10^{-} \\
16\end{array}$ & 0.0 & 0.40 \\
\hline
\end{tabular}

For comparison identical variants to those listed in Supplementary Table S10 are shown here (these variants were identified by fine mapping unconditioned GWAS results from FINRISK and INTERVAL). LD blocks were defined as SNPs that had LD > 0.1 with the lead variant (most significantly associated variant). 
medRxiv preprint doi: https://doi.org/10.1101/2021.12.15.21267719; this version posted December 16, 2021. The copyright holder for this preprint (which was not certified by peer review) is the author/funder, who has granted medRxiv a license to display the preprint in perpetuity.

It is made available under a CC-BY 4.0 International license .

Table 3. Mendelian randomisation results for exposure genetically-determined GDF15 plasma levels with cardiometabolic outcomes.

\begin{tabular}{|c|c|c|c|c|c|c|c|c|c|c|c|}
\hline \multirow[b]{2}{*}{ Methods } & \multicolumn{2}{|c|}{ IVW (fixed) } & \multicolumn{3}{|c|}{ MR-Egger } & \multicolumn{6}{|c|}{ MR-PRESSO } \\
\hline & $\begin{array}{c}\text { Estimate } \\
\text { (SE) }\end{array}$ & $\begin{array}{c}p_{\text {FDR }}(\text { raw } \\
p \text {-value })\end{array}$ & Estimate & $\begin{array}{c}p \text { - } \\
\text { value }\end{array}$ & $\begin{array}{c}\text { Intercept } \\
p \text {-value }\end{array}$ & $\begin{array}{c}\text { Raw } \\
\text { estimate }\end{array}$ & $\begin{array}{c}\text { Raw } p \text { - } \\
\text { value }\end{array}$ & $\begin{array}{c}\text { Outlier } \\
\text { Estimate }\end{array}$ & $\begin{array}{c}\text { Outlier } p \text { - } \\
\text { value }\end{array}$ & $\begin{array}{c}\text { Global } p \text { - } \\
\text { value }\end{array}$ & $\begin{array}{c}\text { Distortion } \\
p \text {-value }\end{array}$ \\
\hline BMI & $\begin{array}{l}-0.006 \\
(0.054)\end{array}$ & $1.0(0.92)$ & $0.043(0.10)$ & 0.67 & 0.57 & $\begin{array}{l}-0.006 \\
(0.054)\end{array}$ & 0.92 & $\begin{array}{l}-0.016 \\
(0.043)\end{array}$ & 0.73 & 0.012 & 0.24 \\
\hline WHR & $\begin{array}{c}0.018 \\
(0.007)\end{array}$ & $\begin{array}{c}0.078 \\
(0.013)\end{array}$ & $\begin{array}{c}0.023 \\
(0.014)\end{array}$ & 0.10 & 0.67 & 0.018 & 0.041 & - & - & 0.075 & - \\
\hline Glucose & $\begin{array}{c}0.019 \\
(0.018)\end{array}$ & $1.0(0.30)$ & $\begin{array}{c}0.010 \\
(0.034)\end{array}$ & 0.77 & 0.76 & 0.019 & 0.34 & - & - & 0.29 & - \\
\hline Diabetes & $\begin{array}{c}0.004 \\
(0.007)\end{array}$ & $1.0(0.52)$ & $\begin{array}{l}-0.003 \\
(0.012)\end{array}$ & 0.80 & 0.46 & $\begin{array}{c}0.004 \\
(0.006)\end{array}$ & 0.47 & - & - & 0.63 & - \\
\hline HDL & $\begin{array}{l}-0.005 \\
(0.004)\end{array}$ & $1.0(0.23)$ & $\begin{array}{l}-0.010 \\
(0.007)\end{array}$ & 0.15 & 0.36 & $\begin{array}{l}-0.005 \\
(0.004)\end{array}$ & 0.27 & $\begin{array}{l}-0.008 \\
(0.005)\end{array}$ & 0.17 & 0.021 & $<0.0002$ \\
\hline BMD & $\begin{array}{c}0.008 \\
(0.009)\end{array}$ & $1.0(0.41)$ & $\begin{array}{l}-0.005 \\
(0.017)\end{array}$ & 0.77 & 0.38 & $\begin{array}{c}0.008 \\
(0.009)\end{array}$ & 0.44 & $\begin{array}{c}0.003 \\
(0.003)\end{array}$ & 0.42 & 0.010 & 0.87 \\
\hline
\end{tabular}

A significant finding of pleiotropy is indicated by the intercept $p$-value in MR-Egger and the Global $p$-value in MRPRESSO. For MR-PRESSO the outlier test is only run if horizontal pleiotropy is observed. The distortion $p$-value represents whether the outlier removal significantly reduces the horizonal pleiotropy. 
medRxiv preprint doi: https://doi.org/10.1101/2021.12.15.21267719; this version posted December 16, 2021. The copyright holder for this preprint (which was not certified by peer review) is the author/funder, who has granted medRxiv a license to display the preprint in perpetuity.

It is made available under a CC-BY 4.0 International license .

Table 4. Reverse Mendelian randomization with GDF15 plasma levels as outcome.

\begin{tabular}{|c|c|c|c|c|c|c|c|c|c|c|c|c|}
\hline \multirow[b]{2}{*}{ Methods } & \multirow[b]{2}{*}{ SNPs } & \multicolumn{2}{|c|}{ IVW (fixed) } & \multicolumn{3}{|c|}{ MR-Egger } & \multicolumn{6}{|c|}{ MR-PRESSO } \\
\hline & & $\begin{array}{c}\text { Estimate } \\
\text { (SE) }\end{array}$ & $\begin{array}{c}p_{\text {FDR }} \\
\text { (raw } p- \\
\text { value) }\end{array}$ & Estimate & $\begin{array}{c}p- \\
\text { value }\end{array}$ & $\begin{array}{c}\text { Intercept } \\
p \text {-value }\end{array}$ & $\begin{array}{c}\text { Raw } \\
\text { estimate }\end{array}$ & $\begin{array}{c}\text { Raw } p \text { - } \\
\text { value }\end{array}$ & $\begin{array}{c}\text { Outlier } \\
\text { Estimate }\end{array}$ & $\begin{array}{l}\text { Outlier } \\
p \text {-value }\end{array}$ & $\begin{array}{c}\text { Global } p \text { - } \\
\text { value }\end{array}$ & $\begin{array}{c}\text { Distortion } \\
p \text {-value }\end{array}$ \\
\hline BMI & 1140 & $\begin{array}{c}0.089 \\
(0.027)\end{array}$ & $\begin{array}{c}0.0072 \\
(0.0012)\end{array}$ & $\begin{array}{c}0.11 \\
(0.081)\end{array}$ & 0.19 & 0.81 & $\begin{array}{c}0.089 \\
(0.027)\end{array}$ & 0.0012 & 0.001 & 0.027 & $<0.00013$ & 0.92 \\
\hline WHR & 577 & $\begin{array}{c}0.021 \\
(0.038)\end{array}$ & $\begin{array}{c}0.83 \\
(0.58)\end{array}$ & $\begin{array}{l}-0.23 \\
(0.12)\end{array}$ & 0.054 & 0.027 & $\begin{array}{l}-0.021 \\
(0.038)\end{array}$ & 0.58 & - & - & 0.0049 & - \\
\hline Glucose & 67 & $\begin{array}{l}-0.024 \\
(0.060)\end{array}$ & $\begin{array}{c}0.83 \\
(0.69)\end{array}$ & $\begin{array}{l}-0.11 \\
(0.14)\end{array}$ & 0.44 & 0.51 & $\begin{array}{c}0.024 \\
(0.060)\end{array}$ & 0.69 & - & - & 0.030 & - \\
\hline Diabetes & 259 & $\begin{array}{l}-0.001 \\
(0.014)\end{array}$ & $\begin{array}{c}097 \\
(0.97)\end{array}$ & $\begin{array}{l}-0.015 \\
(0.034)\end{array}$ & 0.66 & 0.64 & $\begin{array}{c}0.001 \\
(0.014)\end{array}$ & 0.71 & - & - & 0.033 & - \\
\hline HDL & 431 & $\begin{array}{l}-0.056 \\
(0.059)\end{array}$ & $\begin{array}{c}0.68 \\
(0.34)\end{array}$ & $\begin{array}{l}-0.006 \\
(0.097)\end{array}$ & 0.95 & 0.51 & $\begin{array}{l}-0.056 \\
(0.059)\end{array}$ & 0.34 & 0.065 & 0.058 & 0.0033 & $?$ \\
\hline BMD & 1131 & $\begin{array}{c}0.020 \\
(0.017)\end{array}$ & $\begin{array}{c}0.68 \\
(0.24)\end{array}$ & $\begin{array}{c}0.046 \\
(0.035)\end{array}$ & 0.19 & 0.41 & $\begin{array}{c}0.002 \\
(0.017)\end{array}$ & 0.24 & - & - & 0.089 & - \\
\hline
\end{tabular}

A significant finding of pleiotropy is indicated by the intercept $p$-value in MR-Egger and the Global $p$-value in MR-PRESSO. For MR-PRESSO the outlier test is only run if horizontal pleiotropy is observed. The distortion $p$-value represents whether the outlier removal significantly reduces the horizonal pleiotropy. 
medRxiv preprint doi: https://doi.org/10.1101/2021.12.15.21267719; this version posted December 16, 2021. The copyright holder for this preprint (which was not certified by peer review) is the author/funder, who has granted medRxiv a license to display the preprint in perpetuity.

It is made available under a CC-BY 4.0 International license .

\section{Figures}

Figure 1. Forest plots of Cox proportional hazard for independent predictors of (a) allcause mortality, (b) cardiovascular disease and (c) diabetes.

a)

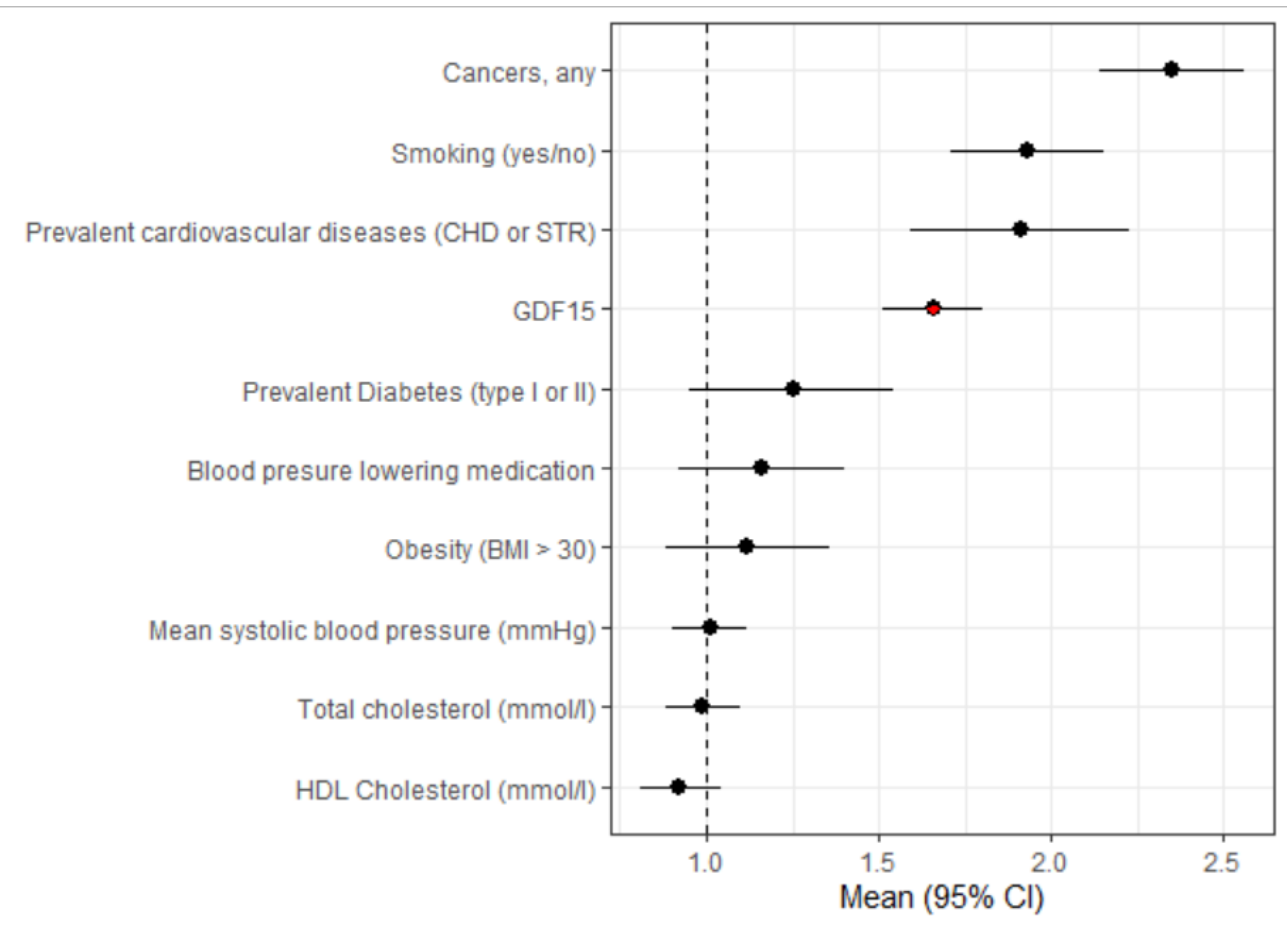

b)

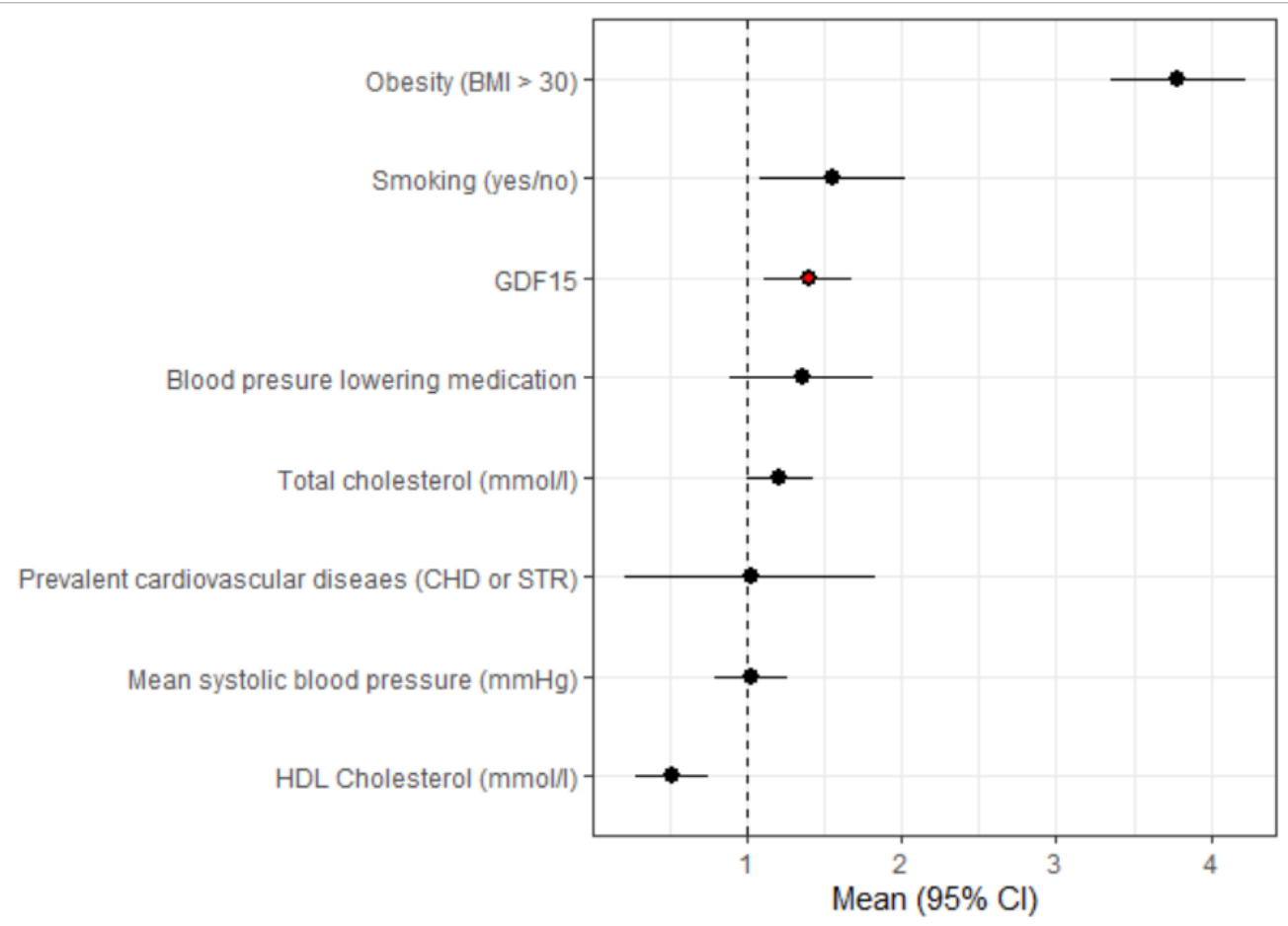


medRxiv preprint doi: https://doi.org/10.1101/2021.12.15.21267719; this version posted December 16, 2021. The copyright holder for this preprint (which was not certified by peer review) is the author/funder, who has granted medRxiv a license to display the preprint in perpetuity.

It is made available under a CC-BY 4.0 International license .

c)

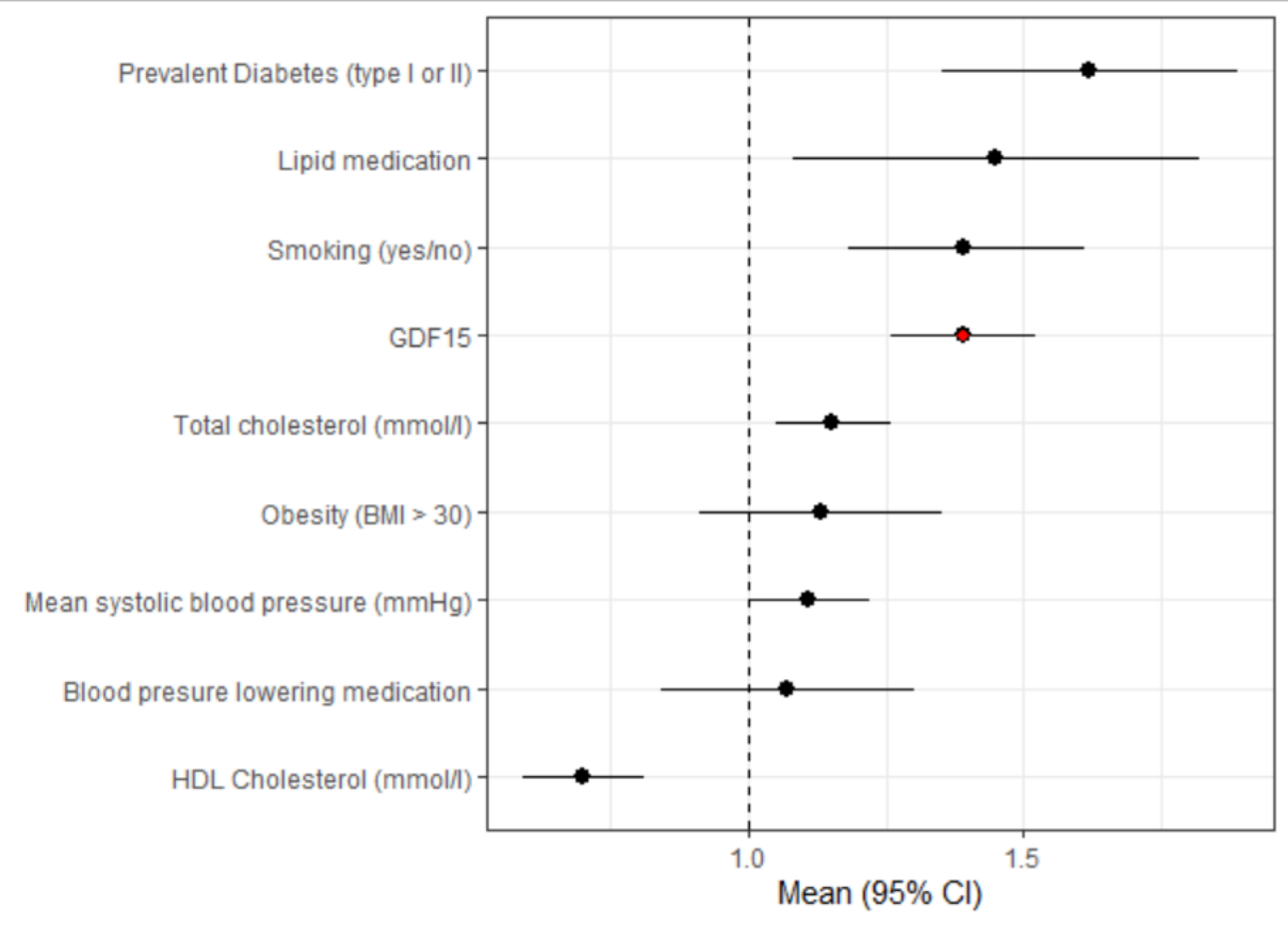

GDF15 is highlighted in red and variables are ordered by highest hazards ratio. Abbreviations: BMI, body mass index; GDF15, growth differentiation factor-15; CHD, coronary heart disease; STR, stroke; HDL, high density lipoprotein. 